\title{
Open-face tunnelling effects on non-displacement piles in clay - part 2: tunnelling beneath loaded piles and analytical modelling
}

\author{
M. G. WILLIAMSON*, R. J. MAIR†, M. D. DEVRIENDT $\dagger$ and M. Z. E. B. ELSHAFIE†
}

\begin{abstract}
Results from centrifuge modelling of tunnelling beneath loaded non-displacement piles in clay are presented in this paper; the principal variables were soil strength, pile loading and pile position relative to the tunnel. The details of the experimental set-up and the importance of understanding the loading history of the soil and the piles are presented in a companion paper. The subsurface pile-soil interaction was captured through particle image velocimetry; the effects of pile loading and pile position were found to have a significant impact on pile settlements. Analysis of tunnel-pile interaction through $t-z$ load-transfer modelling of the pile-soil interface is presented using the approach described in the companion paper. The mechanisms observed in the centrifuge tests are predicted reasonably well. A significant improvement in the prediction of the induced pile loading and settlements was achieved with the inclusion of plasticity and simple power-law non-linearity for the soil.
\end{abstract}

KEYWORDS: piles \& piling; soil/structure interaction; tunnels \& tunnelling

\section{INTRODUCTION}

The need for a better understanding of the interaction between new tunnel construction schemes and existing infrastructure supported by deep foundations is becoming increasingly relevant with the construction of major tunnelling schemes in cities. Of particular interest is the effect of tunnelling beneath non-displacement (bored) piles in clay. However, research on this topic has, to date, been significantly less in comparison with research on driven piles, despite the majority of deep foundations in urban areas using non-displacement piles.

Industry practice has been relatively conservative when assessing the effects of tunnelling on piles, despite an increasing body of analytical and numerical work indicating the conservatism. One of the reasons for this is a general lack of high-quality experimental data (from, for example, centrifuge modelling) or case history data from the field, particularly in relation to the effects of tunnelling beneath piles in clay as opposed to the effects of tunnelling adjacent to piles.

On the other hand, recent analytical and numerical works in the area of tunnelling on piles are extensive. Analytical works have generally taken the form of the two-step approach method (TSAM) (Chen et al., 1999), in which the assumed 'greenfield' settlements are used as input to either a boundary-element analysis or $t-z$ load-transfer analysis. More recent analyses, such as those reported by Kitiyodom et al. (2005), Huang et al. (2009), Zhang et al. (2011), Zhang et al. (2013) and Basile (2014), have focused on pile groups and how to best model interaction factors between adjacent piles for linear elastic and non-linear elastic load-transfer curves. Such methods have proved to be reasonably successful

Manuscript received 30 January 2017; revised manuscript accepted 9 August 2017. Published online ahead of print 11 September 2017. Discussion on this paper closes on 1 April 2018, for further details see p. ii.

Published with permission by the ICE under the CC-BY 4.0 license. (http://creativecommons.org/licenses/by/4.0/)

* Mott MacDonald Limited, Cambridge, UK (formerly University of Cambridge, Cambridge, UK).

$\dagger$ Department of Engineering, University of Cambridge, Cambridge, UK.

† Ove Arup and Partners Limited, London, UK for the back-analysis of centrifuge and field data associated with tunnelling adjacent to piles (using centrifuge and field data reported by Loganathan et al. (2000) and Pang et al. (2005), respectively). Numerical analyses, such as those of Mroueh \& Shahrour (2002), Lee \& Ng (2005) and Cheng et al. (2007), used the same centrifuge and field data for back-analysis, again with the emphasis on tunnelling adjacent to piles.

More recent work (e.g. Lee, 2012a, 2012b, 2013) has moved beyond simple comparisons with data to understand the underlying mechanisms, but these analyses have been limited by a lack of centrifuge and case study data, particularly data relating to the subsurface soil-pile behaviour. The novel centrifuge set-up described in a companion paper to the current article (Williamson et al., 2017), which combines the use of particle image velocimetry (PIV) and an innovative model pile and pile loading system, enables high-quality data to be produced. The data provide a more fundamental understanding of the effects of tunnelling beneath loaded piles in clay.

The centrifuge programme and the results are presented in this paper. The paper also presents the use of a TSAM for a non-linear elastic-perfectly plastic load-transfer mechanism, based on a power-law stress-strain model, which is applied for known subsurface displacements taken from a 'greenfield' centrifuge test.

\section{BACKGROUND}

The use of 'greenfield' settlements at pile toe level (i.e. ignoring the presence of the pile) to predict pile head settlements has been seen as most relevant to tunnelling beneath end-bearing piles in sands; it has been shown by Jacobsz et al. $(2004,2005)$ to be appropriate for such situations. For non-displacement piles in clay, such an approach is likely to be conservative because piles in clay are usually designed to be shaft-controlled (Tomlinson \& Woodward, 2008). Diagrams have been used to represent a relation between the pile displacements and the soil displacements around the tunnel; depending on the pile toe position relative to the tunnel (according to defined zones), such diagrams attempt to assess whether the pile settlements are larger than, equal to, or smaller than the ground surface settlements at the pile head. Such diagrams have been 
proposed by a number of authors, including Jacobsz (2002), Kaalberg et al. (2005) and Selemetas et al. (2005), but they are limited to the ground conditions upon which they were derived and do not take account of individual pile loading.

Other approaches include identifying the position of the neutral axis in the pile (the point of zero shear stress in the pile); the pile is assumed to be rigid with a perfectly plastic pile-soil load-transfer curve. The greenfield tunnellinginduced settlement at the neutral axis is assumed to represent the pile head displacement; this is the simplest of the $t-z$ TSAM analyses. The neutral-axis approach takes account of the pile head load, the pile factor of safety $(\mathrm{FoS})$ and, in some cases, the base response (Williamson, 2014). This neutral-axis approach can be applied in closed form to a number of scenarios, as shown by Williamson (2014), with uniform and linearly increasing strength profiles subjected to settlement profiles that either continuously increase or decrease with depth; other strength profiles can be simply assessed either graphically or numerically in a spreadsheet. For settlement profiles that neither increase nor decrease with depth, the analysis is less simple and requires iteration.

A further advancement in this approach has been the adoption of TSAM boundary-element modelling (BEM) analyses, first proposed by Chen et al. (1999), who applied the approach for tunnelling beneath single piles. Jacobsz et al. (2005) described the 'reserve shaft capacity' as an important component when assessing the expected pile head displacements when subjected to tunnelling beneath piles; however, this was not quantified. The TSAM for $t-z$ and BEM analyses takes account of the reserve shaft capacity condition as a matter of course. BEM methods are a family of solutions that are linear elastic in nature and apply the Mindlin (1936) solution, based on the Kelvin and Boussinesq formulations, for loading of a circular ring in an infinite half-space for the shaft and a rigid circular punch for the base. Interaction factors are applied within the piles under consideration between the discretised pile elements. $t-z$ analyses are a subset of BEM analyses; however, interaction factors between the discretised pile elements are not taken into account and as such are less rigorous, although they are advantageous in the simplicity of the formulation and the ability to apply any load-transfer curve to a given loading scenario. The analysis reported by Chen et al. (1999) was uncoupled between the vertical and horizontal displacements, while Loganathan et al. (2001) presented results for a coupled analysis between vertical and horizontal pile displacements using the BEM analysis code, Gepan (Xu \& Poulos, 2001). However, the Gepan code, unlike the uncoupled Chen et al. (1999) analysis, was unable to model the plastic effect of pile slip (limiting skin friction), which has been shown to be significant when modelling tunnelling beneath piles (Williamson, 2014).

Significant analytical research work relevant to this paper includes the following.

(a) Kitiyodom et al. (2004) and Klar \& Soga (2005) applied a linear elastic Winkler spring $t-z$ analysis to the problem of tunnelling adjacent to piles, whereas Huang et al. (2009) expanded this work for pile-to-pile interaction. Kitiyodom et al. (2005) applied a method (the Prab code) based on a hybrid model that combines load-transfer analysis for a single pile response with a Mindlin-based BEM analysis to evaluate pile-soil-pile interaction. The code took into account the increased complexity of the pile head condition for piled rafts.

(b) A non-linear $t-z$ analysis was applied by Zhang et al. (2011) using a hyperbolic tangent (tanh) model for the load-transfer function, which effectively allowed slip due to the shape of the tanh function. Zhang et al.
(2011) applied the interaction effect within a pile group using the logarithmic decay proposed by Randolph \& Wroth (1978), assuming that the soil between piles is likely to behave linear elastically and any large strain behaviour would be localised to the pile shaft, following the work reported by Chow (1986).

(c) Korff (2012) applied the tanh function to model timber piles when subjected to tunnelling displacement profiles and produced a series of design charts for piles in soft clay.

(d) Huang \& Mu (2012) noted that the internal interaction effects due to element-on-element loading resulted in greater pile axial loading and vertical displacements than for $t-z$ models. Huang \& Mu (2012) applied a method similar to BEM based on the Mindlin (1936) solutions for piles in layered soils; however, the method assumed linear elasticity and did not allow any pile-soil slip.

(e) Basile (2014) presented a non-linear BEM solution for pile groups that took soil non-linearity at the soil-pile interface into account. The model used an incremental solution, allowing soil-pile slip with the soil modelled using a hyperbolic stress-strain model. The soil modulus at the interface used in the calculations was incrementally varied and averaged; although this is in contradiction to the homogeneity condition, this approach is often applied to BEM analyses, following the work of Poulos \& Davis (1980).

Finite-element modelling of tunnelling beneath piles has been used by a number of researchers (Mroueh \& Shahrour, 2002; Yoo \& Kim, 2008; Lee, 2012a, 2012b, 2013; Yoo \& Wu, 2012). Many of these studies looked at the effects of pile groups, although without high-quality case studies for comparison of the results.

All TSAMs predict the maximum pile head settlement (due to tunnelling) to be limited to the range of displacements between greenfield pile head and pile toe displacements; in the case where subsurface settlements are greater than those at both the pile head and the pile toe, TSAMs may predict pile head settlements greater than those at both the pile head and pile toe. The centrifuge models of Jacobsz et al. (2004) and Marshall \& Mair (2011), which investigated end-bearing piles in sand, showed vertical pile head displacements in excess of the 'greenfield' settlements along the depth of the pile shaft, in which the base had undergone a loss of base capacity. Data from the field studies of both Selemetas et al. (2005) and Jacobsz et al. (2005) for tunnelling beneath piles in clays showed displacements that were larger than the greenfield soil surface settlements where no remedial measures had been applied, but lower than the greenfield settlements at the pile toe, as would be predicted for a single pile using the TSAM. Williamson (2014) describes two case studies for buildings supported by piled foundations affected by the Crossrail tunnelling works where the pile head displacements closely matched the ground surface settlements despite tunnelling directly underneath the piles under consideration. However, this was thought to be due to a combination of load transfer in the upper piles/pile caps/ground beams and higher than assumed FoS values. A centrifuge study carried out by Lee \& Chiang (2007), while unable to correctly model the mechanism between shaft loading and tunnelling movements, did illustrate the important influence of the pile FoS on pile head displacement due to tunnelling.

In summary, it is clear from the literature that the effect of tunnelling beneath non-displacement piles in clay is significantly less researched in comparison with driven piles and hence the response of these piles is not well understood. As a result, conservative approaches are taken when assessing 
tunnelling effects on these piles, mainly relying on analytical or numerical approaches, which require high-quality data either from centrifuge studies or case history data for validation, which are not presently available. It is also clear, from the literature, that a number of variables are considered to have a significant impact on pile head displacements when a pile is subjected to tunnelling-induced ground movements. These variables are

(a) the initial pile shaft and base loading

(b) the pile FoS in relation to the base and shaft

(c) relative pile/soil stiffness

(d) pile position relative to the tunnel

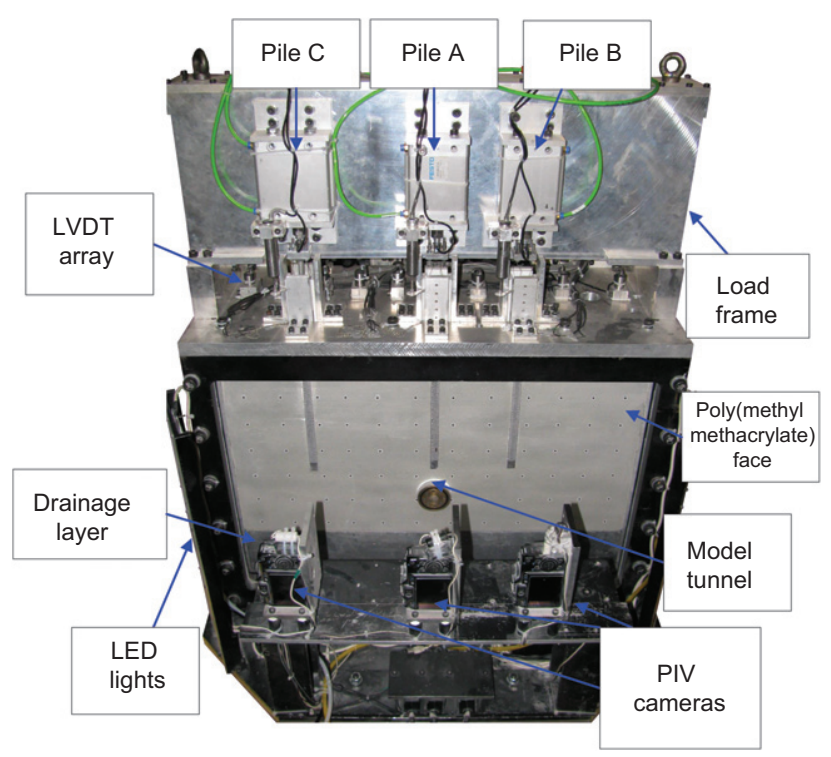

(a)

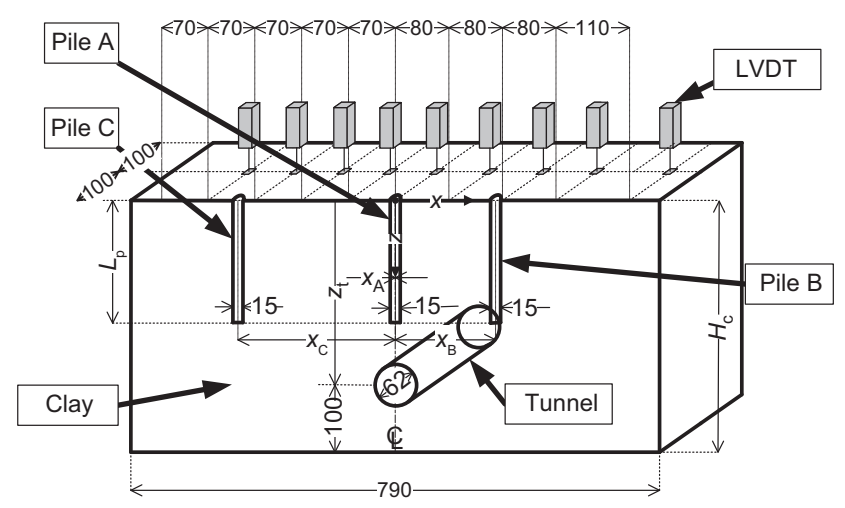

(b)

Fig. 1. Experimental set-up: (a) photograph; (b) schematic illustration (dimensions in $\mathrm{mm}$ ). LVDT, linear voltage differential transducer; LED, light-emitting diode (e) pile spacing and position within a group

$(f)$ the soil settlement profile and ground conditions

$(g)$ the susceptibility of the pile to cracking under tension

(h) pile head loading conditions (details of the pile cap).

\section{CENTRIFUGE TESTING}

High-quality data that could be used to validate numerical and analytical models and provide a more fundamental understanding of tunnel-soil-pile mechanisms are very scarce. Therefore, a research programme was conducted using the geotechnical centrifuge at the University of Cambridge (Schofield, 1980) to investigate the interaction effects of tunnelling beneath non-displacement piles in clay (using plane-of-symmetry conditions). The relevance of plane-of-symmetry centrifuge modelling to provide data on subsurface soil-structure interactions and the load-transfer mechanisms for tunnelling under piles was important, given the need for calibration and verification of both analytical TSAMs and three-dimensional (3D) finite-element modelling. In particular, the research programme investigated the effects of

(a) pile FoS

(b) pile position relative to the tunnel

(c) relative pile/soil stiffness.

Other factors were also investigated in this research programme, but are not presented here (see Williamson, 2014). The centrifuge apparatus used to conduct the experiments is shown in Fig. 1. The model pile positions (relative to the tunnel), the head loads on the model piles and the associated safety factors are described in Table 1. Table 1 also summarises the tests $(\mathrm{G}, \mathrm{PC} 2, \mathrm{PC} 4, \mathrm{PC} 5$ and PC6) presented in this paper in which the three factors listed above were investigated to gain a detailed understanding of the tunnelpile-soil interaction mechanisms involved. Tests PC2, PC4, PC5 and PC6 consisted of three strain-gauged model piles in three different locations (A, B and $\mathrm{C}$ ). Locations $\mathrm{A}$ and $\mathrm{B}$ (relevant to this paper; location $\mathrm{C}$ is discussed in detail in the companion paper in relation to pile load test behaviour) and the depth of the strain gauges are shown in Fig. 2. In each of the four tests with piles presented in this paper (tests PC2, PC4, PC5 and PC6), piles A and B were located as shown in Fig. 2. In the rest of the paper, pile A-PC2 refers to the model pile at location A (as shown in Fig. 2) in test PC2, pile B-PC6 refers to the model pile at location B in test PC6, and so on.

Each centrifuge test underwent the following phases, which are discussed in this paper.

(a) Consolidation stage following centrifuge spin up to $75 \mathrm{~g}$.

(b) Initial pile loading to a specified FoS.

(c) Simulation of volume loss through tunnel excavation beneath the piles

Table 1. Summary of experiments

\begin{tabular}{|c|c|c|c|c|c|c|c|}
\hline \multirow[t]{2}{*}{ Experiment } & \multicolumn{3}{|c|}{ Pile A } & \multicolumn{3}{|c|}{ Pile B } & \multirow[t]{2}{*}{ Test type } \\
\hline & $\begin{array}{l}\text { Toe position, } \\
x_{\mathrm{A}}, L_{\mathrm{p}}: \mathrm{mm}\end{array}$ & $\begin{array}{c}\text { Head load, } \\
P_{\mathrm{A}}: \mathrm{N}\end{array}$ & FoS & $\begin{array}{c}\text { Toe position, } \\
x_{\mathrm{B}}, L_{\mathrm{p}}: \mathrm{mm}\end{array}$ & $\begin{array}{c}\text { Head load, } \\
P_{\mathrm{B}}: \mathrm{N}\end{array}$ & FoS & \\
\hline G (greenfield - no piles) & - & - & - & - & - & - & 'Greenfield' test with no piles \\
\hline $\mathrm{PC} 2$ & 0,216 & $118 \cdot 7$ & $2 \cdot 85$ & 150,216 & $130 \cdot 4$ & $2 \cdot 60$ & Reference \\
\hline PC4 & 0,216 & $164 \cdot 0$ & 1.99 & 150,216 & $168 \cdot 2$ & 1.94 & Lower FoS \\
\hline PC5 & 0,216 & $86 \cdot 6$ & $2 \cdot 62$ & 150,216 & $70 \cdot 2$ & $3 \cdot 23$ & Lower strength/stiffness \\
\hline PC6 & $-75,216$ & $114 \cdot 8$ & $2 \cdot 95$ & 150,185 & $77 \cdot 0$ & $3 \cdot 42 *$ & Pile position - offset \\
\hline
\end{tabular}

*Estimated from PC2/PC4. 


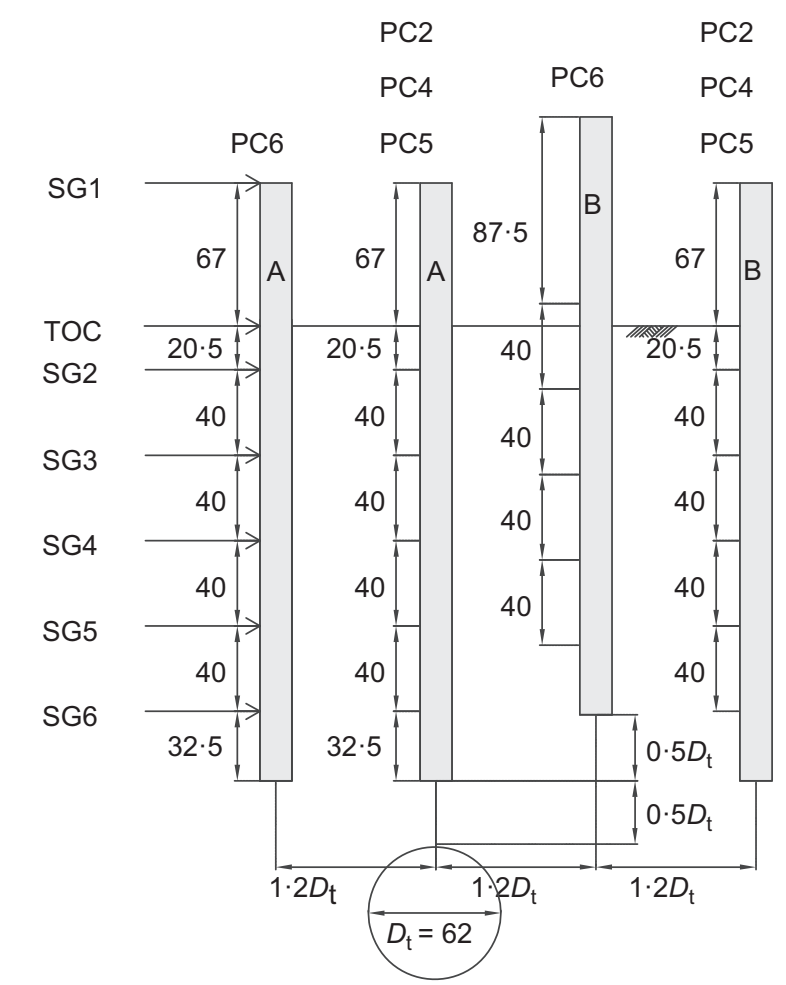

Fig. 2. Pile positions relative to the tunnel (dimensions in $\mathbf{m m}$ ). TOC, top of clay

Details of the experimental set-up, instrumentation and the pile loading techniques are described in the companion paper (Williamson et al., 2017).

The results of the centrifuge study are presented in this paper alongside non-linear elastic-perfectly plastic $t-z$ analyses as described in the section entitled 'Comparison with 'greenfield' settlements and analytical modelling'. Owing to the chosen set-up of single piles, the variation between the $t-z$ and BEM analyses was expected to be small, and the $t-z$ analysis provided more flexibility for varying the load-transfer mechanism and soil stiffness with depth.

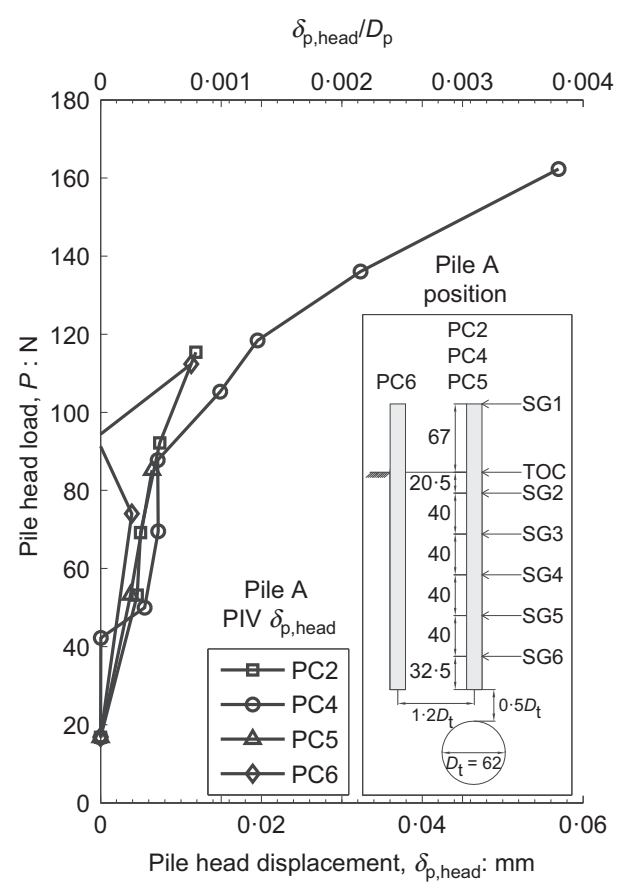

INITIAL PILE LOADING STAGE

Pile head loading was applied following a period of consolidation in the centrifuge at $75 \mathrm{~g}$; the end of this consolidation period was determined when further changes in pore water pressure measured within the soil body were negligible. The model piles (at locations A and B) were then loaded incrementally, using the loading apparatus shown in Fig. 1, until the entire dead load of the pile cap was taken by the pile; the piston was then allowed to fully extend to ensure the pile head was free to move vertically. The pile head loadsettlement results are shown in Fig. 3: the load-settlement behaviour is relatively linear elastic, with the exception of test PC4 which had the lowest FoS and as such shows non-linearity in the initial phase. Although not shown in Fig. 3, continued displacement at a constant head load (during the stabilisation period) was seen following load completion; this was a function of soil creep, not consolidation, as the strain gauge measurements in the model pile did not vary during the stabilisation period. The inferred loads from the strain gauges embedded inside the model piles are shown plotted against pile head displacement in Fig. 4.

The load profile with depth prior to and following head loading for each of the piles is shown in Fig. 5, alongside the change in pile load with depth. The piles showed very little load transfer in the upper region, with the majority of the applied head load being supported at depth; this is most visible in the change in load plot $(\Delta F)$ as these values were nearly constant in the upper $60 \mathrm{~mm}$ depth. The final profiles indicate the presence of some base loading for the majority of the piles; in particular both piles A and B for PC4. Initially, prior to loading, the upper clay would appear to be at or close to its limiting positive skin friction whereas the lower part of the pile was initially subjected to negative skin friction that was reversed on application of the head load.

The PIV equipment, shown in Fig. 1(a), was used to provide data on the relative pile-soil displacement, which is plotted against the inferred shaft friction in Fig. 6. The load-transfer curves show that the upper part of the pile was at or close to its limiting skin friction value. The load-transfer curves in the lower part of the pile show stiff responses upon stress reversal from initially being subjected to negative

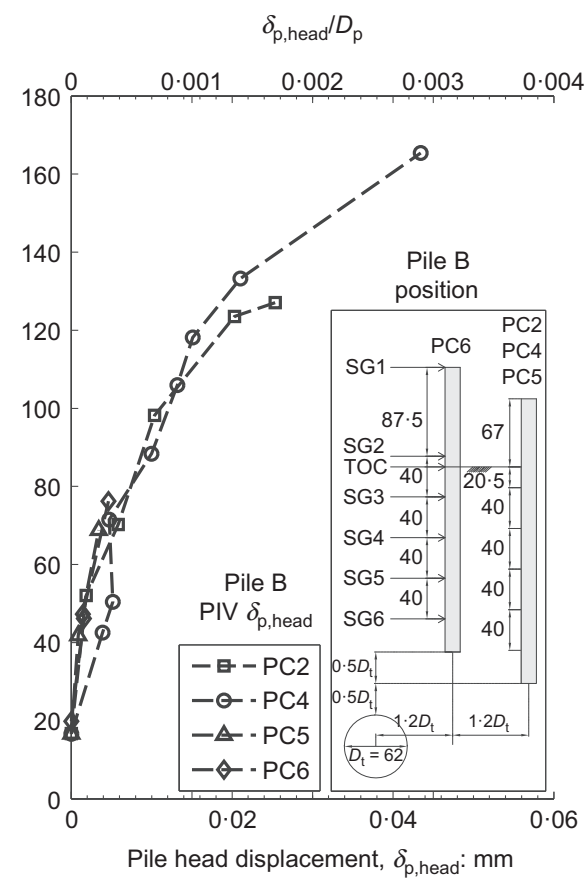

Fig. 3. Initial load test: piles A and B. TOC, top of clay 

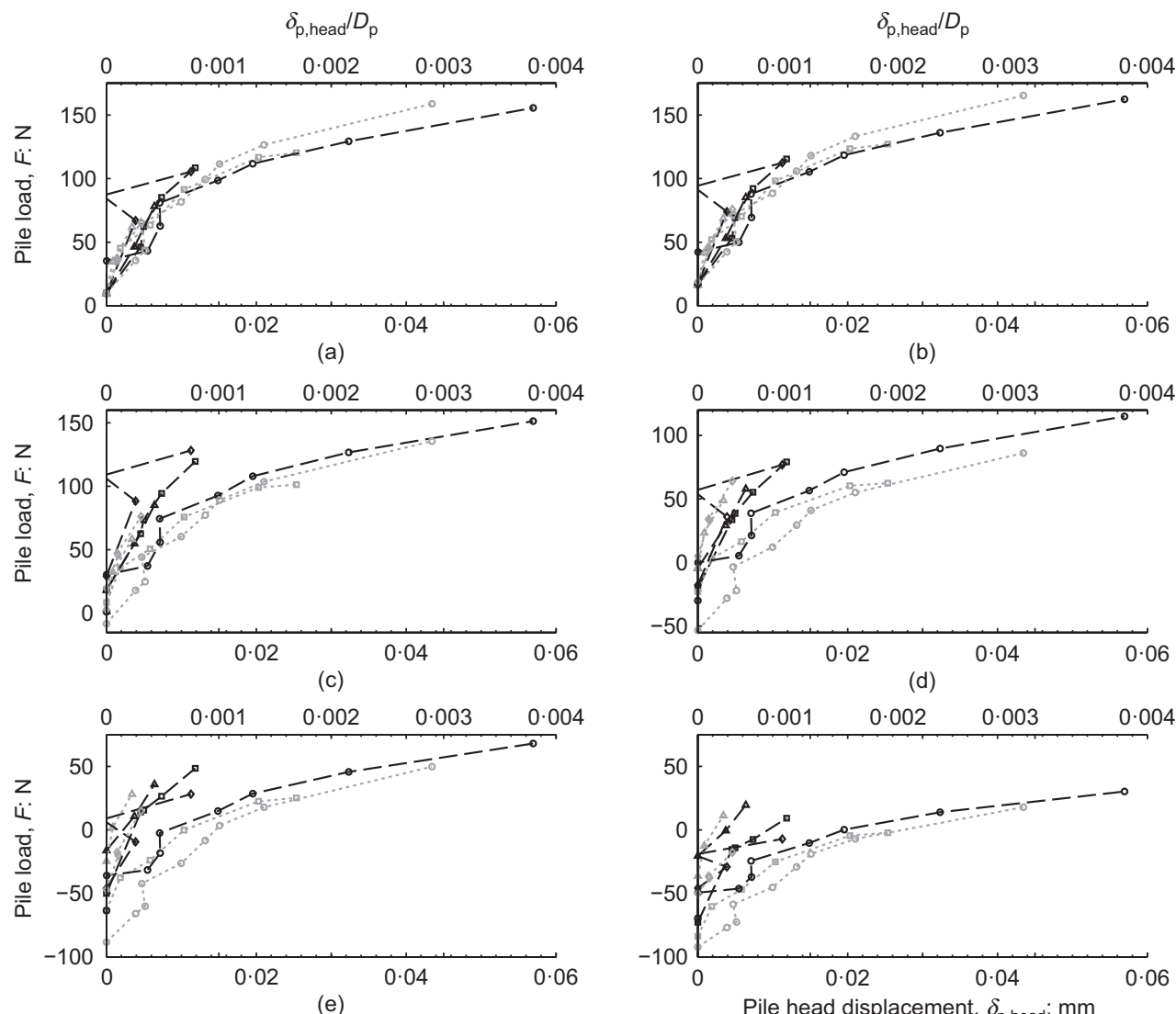

(f)
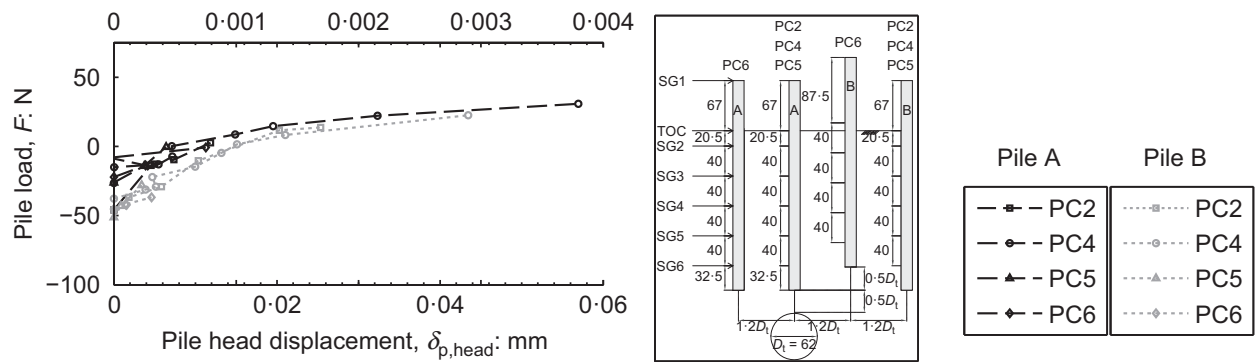

(g)

Fig. 4. Strain gauge inferred load plotted against pile head displacement: (a) SG1; (b) top of clay (TOC); (c) SG2; (d) SG3; (e) SG4; (f) SG5; (g) SG6

skin friction; this can be seen when compared with the strain gauges higher up the piles. The lower strain gauges (SG5 and SG6 shown in Fig. 2) exhibited a non-linear load-transfer mechanism, which can most easily be seen for PC4 piles A and B.

Values of shaft adhesion were calculated using the strength profiles given by Williamson et al. (2017). The shaft adhesion factors $(\alpha)$ for each pile segment were calculated to be limited to \pm 0.7 for tests PC2, PC4 and PC6 where the preconsolidation pressure was $800 \mathrm{kPa}$ (average $c_{\mathrm{u}}=80 \mathrm{kPa}$ ) and \pm 0.9 for test PC5 where the pre-consolidation pressure was $400 \mathrm{kPa}$ (average $c_{\mathrm{u}}=50 \mathrm{kPa}$ ). Such values are generally consistent with the maintained load tests to failure at the pile C location (Williamson et al., 2017), which were average values for the entire pile shaft.

\section{PILES SUBJECTED TO TUNNELLING VOLUME LOSSES FOLLOWING INITIAL PILE LOADING STAGE}

Following the initial pile loading stage described in the previous section, steadily increasing tunnelling volume losses were then applied beneath the model piles. The pile head displacements obtained from the PIV data are plotted against volume loss in Fig. 7.

The pile head load had a significant effect on pile head displacement for pile A-PC4, showing approximately 25\% greater displacements for the same volume loss as pile A-PC2. Pile A-PC5 showed a very similar displacement to pile A-PC2, as might be expected given the similar global FoS. Pile A-PC6 shows much lower displacements than the other pile A tests, as expected given the lower soil settlements away from the tunnel centre-line.

Piles B-PC2 and B-PC5 showed similar pile displacements while pile B-PC4 showed significantly greater displacements. Pile B-PC6 exhibited unusual displacement behaviour, as all of the other pile-tunnel experiments showed relatively linear increases with volume loss; this was due to a skewing of the soil settlements throughout the model towards pile A-PC6. The final pile displacements at 5\% volume loss were greater than those of the other tests, as might be expected given the pile position and safety factors.

The relationship between the pile displacement normalised by the soil surface settlement at the pile head (measured by 

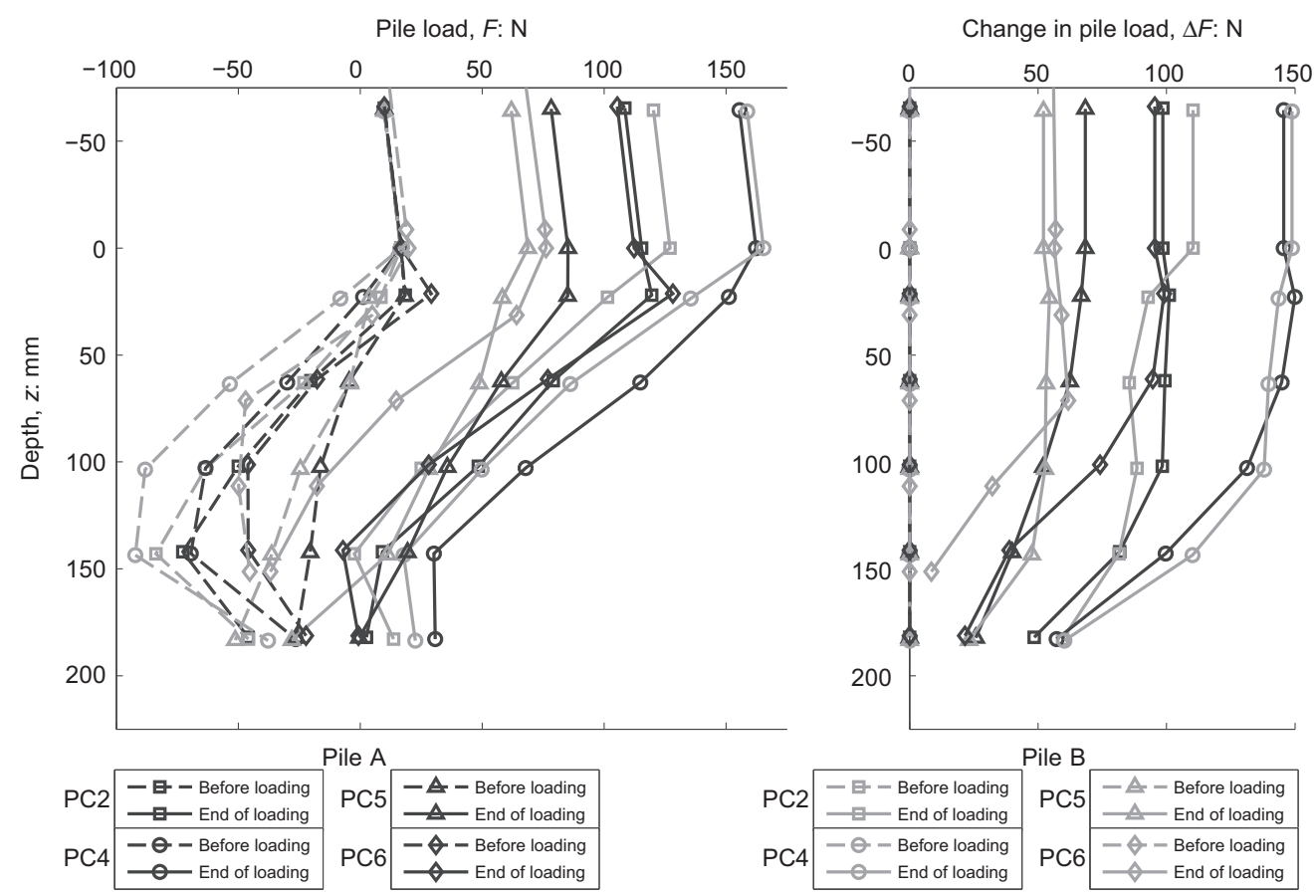

Fig. 5. Pile load and change in pile load plotted against pile depth
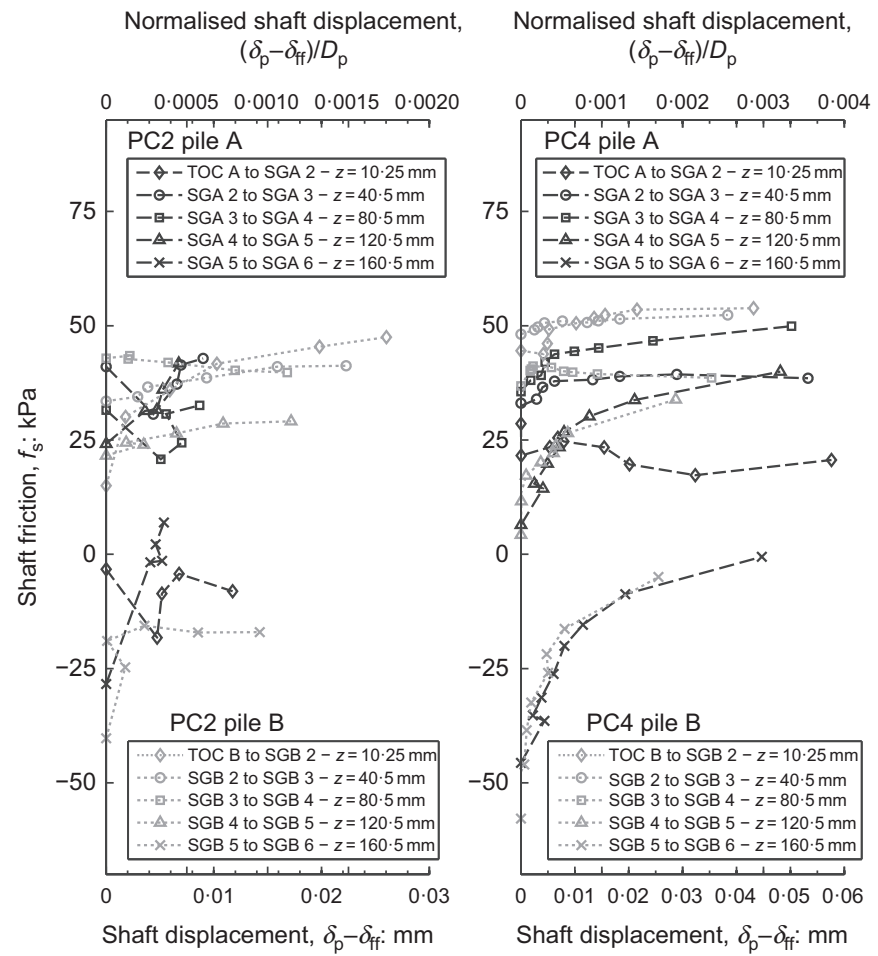

Normalised shaft displacement, $\left(\delta_{\mathrm{p}}-\delta_{\mathrm{ff}}\right) / D_{\mathrm{p}}$

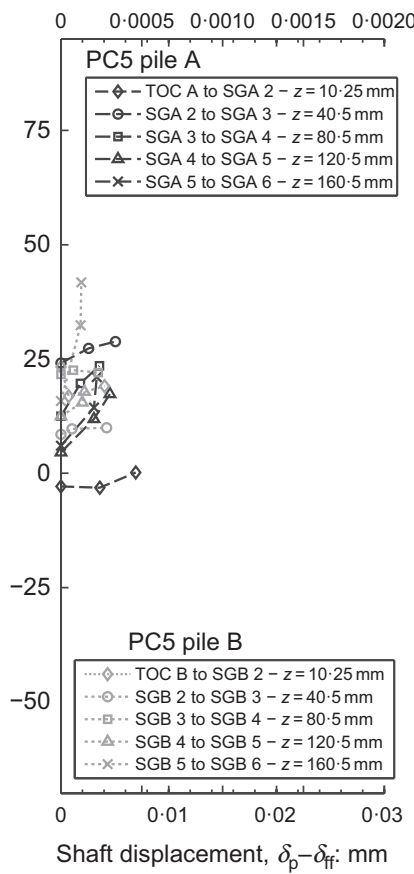

Normalised shaft displacement $\left(\delta_{\mathrm{p}}-\delta_{\mathrm{ff}}\right) / D_{\mathrm{p}}$

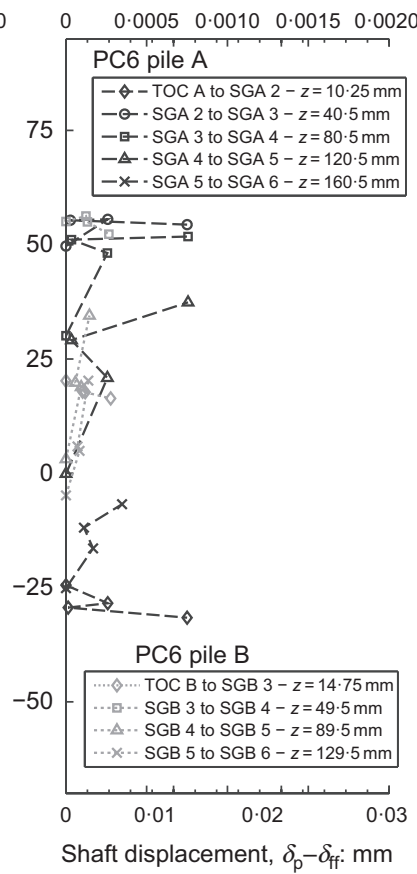

Fig. 6. Shaft friction plotted against relative displacement. TOC, top of clay

linear voltage differential transducers (LVDTs)) and volume loss is shown in Fig. 8. For pile A, the normalised settlements of the centre-line piles (A-PC2, A-PC4 and A-PC5) were all consistently greater than unity, with pile A-PC4 significantly greater. Each of the centre-line piles exhibited different initial values before stabilising between $2 \%$ and $5 \%$ volume loss. When considering the variation between piles B-PC2, B-PC4 and B-PC5, the normalised settlements of pile B-PC4 were greater than unity, which was unexpected given the reducing settlement with depth profile at this location. Piles B-PC2 and B-PC5 showed similar normalised settlements less than unity, while pile B-PC6 showed values lower than unity; however, the normalised displacements continued to increase with volume loss.

The pile loads inferred from the strain gauge measurements are plotted against depth for different volume losses in Fig. 9. The plots show that the head load remained constant with volume loss, but the pile underwent changes in its load distribution due to relative pile-soil displacement applying shear stresses to the pile. The centre-line piles (A-PC2, A-PC4 and A-PC5) showed increasing soil settlement profiles with depth, inducing a reduction in the measured loads along the pile length. The deepest strain gauge (SG6) showed a reduction in load, indicating a reduction in base 


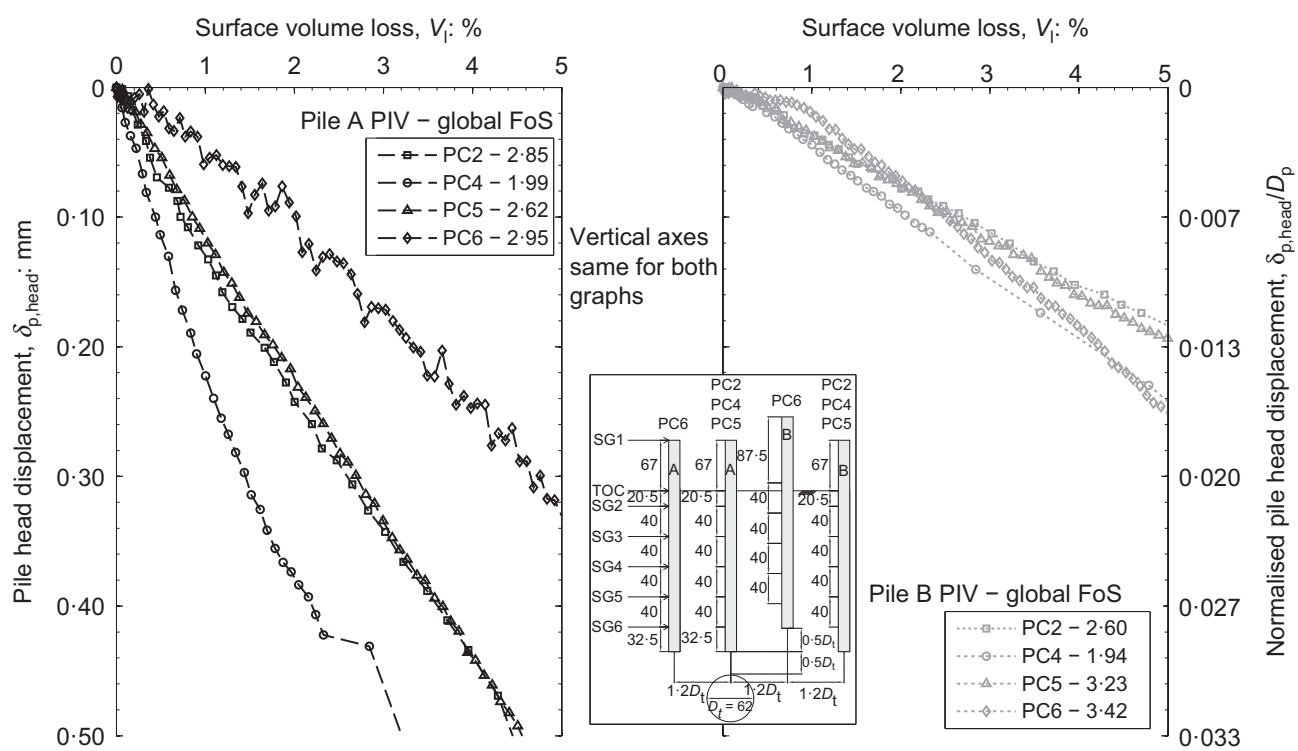

Fig. 7. Volume loss plotted against pile head displacement. TOC, top of clay
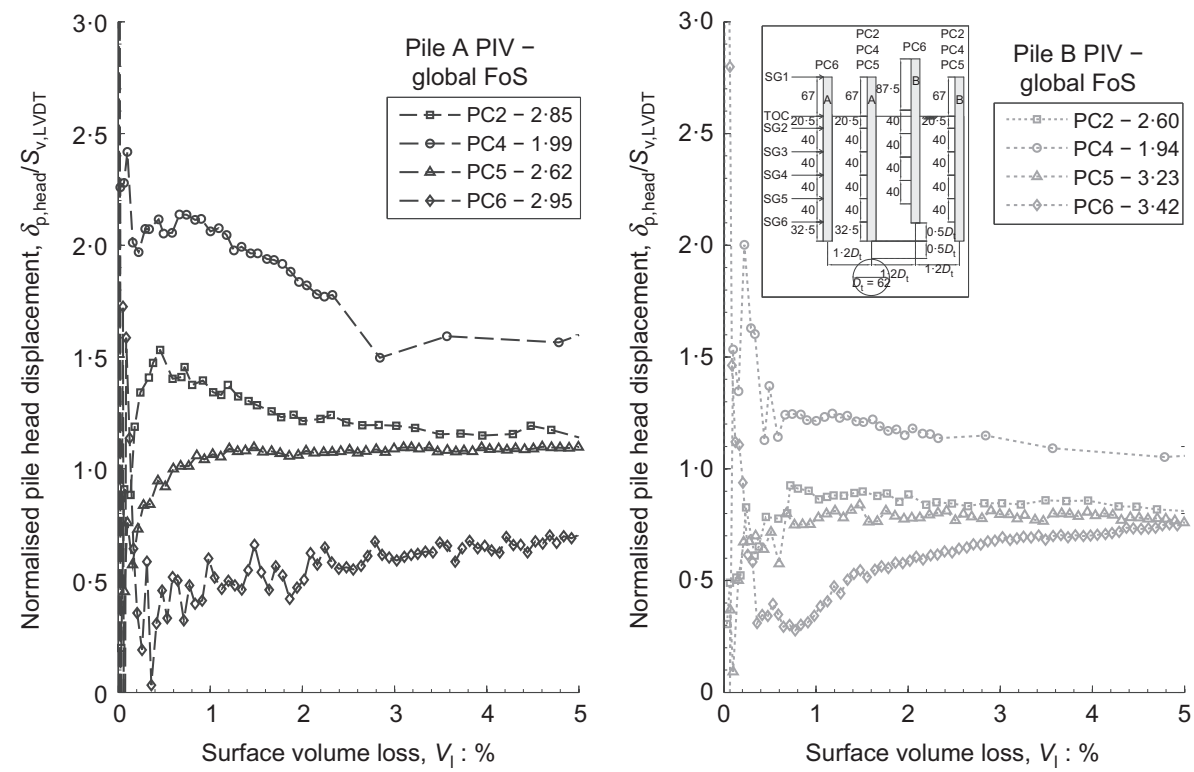

Fig. 8. Normalised pile head displacement plotted against volume loss. TOC, top of clay

load/shaft friction in the lower part of the pile. The change in load was generally small with the majority at low volume losses $(<2 \%)$, except for pile A-PC6 where the change was more gradual with increasing volume loss. Pile A-PC6 showed an increase in loading with depth owing to the soil settlement profile reducing towards the pile base, resulting in an increase in base load/shaft friction in the lower part of the pile. Piles B-PC2, B-PC4 and B-PC5, which were $150 \mathrm{~mm}$ horizontally from the tunnel centre-line, all showed increases in pile load throughout, and in particular towards the base. Similar to pile A-PC6, all piles experienced increasing soil settlement profiles with depth. Pile B-PC6 also showed an increase in load throughout, although the increase in load at mid-depth $(100 \mathrm{~mm})$ was greater than that at the pile toe, which agrees well with the PIV-measured soil settlements in test $\mathrm{G}$ around this location.

The shaft friction measured between strain gauges is plotted in Fig. 10 as a function of surface volume loss. The changes in shaft friction were generally small. A comparison between piles A-PC2/A-PC5 and A-PC4 shows a variation in behaviour in the respective deepest portions of the piles, with piles A-PC2/A-PC5 showing a reduction in skin friction and pile A-PC4 showing an increase in skin friction. This difference is due to the increased head load in pile A-PC4 resulting in a deeper neutral axis than for pile A-PC2 to maintain equilibrium. Hence positive relative displacement occurred to a greater depth for pile A-PC4 with less of the lower part of the pile experiencing downdrag than pile A-PC2/A-PC5. Pile A-PC6 showed a reduction in shaft friction in the upper pile due to downdrag, which was balanced by an increase in shaft friction in the lower pile due to positive relative displacement. Piles B-PC2, B-PC4 and B-PC5 showed relatively small changes, with all piles exhibiting some downdrag due to negative relative displacement. Pile B-PC6 showed the greatest change in shaft friction as well as an increase in shaft friction in the lower part of the pile due to positive relative displacement.

PIV-measured vertical and horizontal displacements for the greenfield test (test G) and tests PC2, PC4, PC5 and PC6 are shown at a volume loss of approximately 5\% in Fig. 11. 

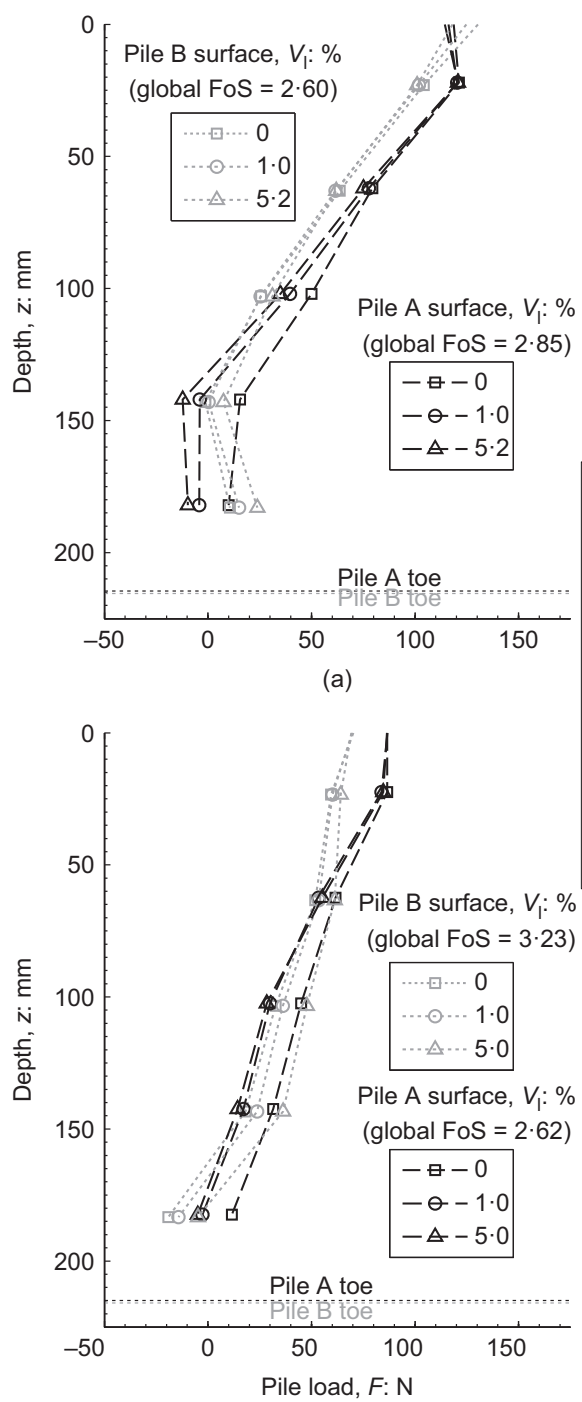

(c)
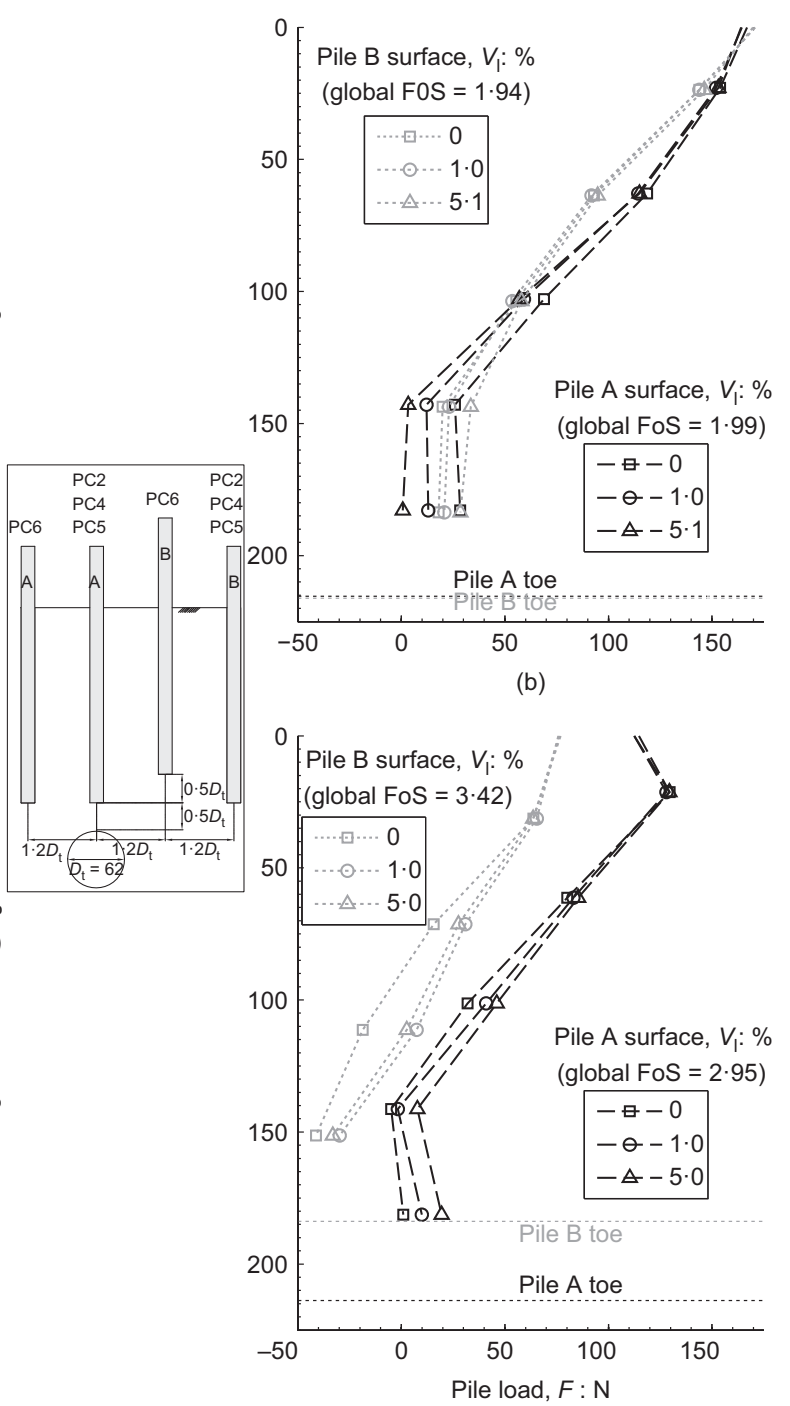

(d)

Fig. 9. Variations in pile load with volume loss. (a) PC2: reference test; (b) PC4: low FoS test; (c) PC5: low $E_{\text {soil }}$ test; (d) PC6: offset test

The magnitude and extent of the vertical settlements were generally consistent; a greater effect of the piles was seen in the horizontal movements, particularly for PC6. In the pile tests, the displacements in the far field were consistent with one another, both in terms of the shape of the displacement bulbs and the displacement magnitudes, although the displacements around the piles are a function of strength mobilisation of the clay and the pile position. Test PC5 showed greater subsurface displacements in the region of both piles when compared with the other tests. Lower strength clay (average $c_{\mathrm{u}}=50 \mathrm{kPa}$ ) was used in test PC5; thus, for the same volume loss (a function of soil shear strain) the movements between the piles were more significant than in PC2 (average $c_{\mathrm{u}}=80 \mathrm{kPa}$ ), despite the similar global FoS. Test PC6 showed similar displacements away from the piles as test PC2, although what is more evident than in the other tests is some lateral drag of both piles towards the tunnel.

PIV-measured shear strains (at a volume loss of approximately 5\%) are shown in Fig. 12(a) for greenfield test $\mathrm{G}$ and tests PC2, PC4, PC5 and PC6; the shear strains were calculated using the methodology described by Marshall \& Mair (2011) with an approximate error due to the PIV resolution of $0 \cdot 30 \%$ and a standard deviation of $0 \cdot 12 \%$. The shearing mechanism seen in test $\mathrm{G}$ without the influence of a pile was similar to that found by Mair (1979), with 'wolf-ears' emanating from the tunnel shoulders. This mechanism was also visible in the pile tests, although the presence of the piles increased the shear strains above the tunnel compared to test G. The shear strains at the pile interface are indicative of the relative displacements or pile slip, particularly in the upper layers. Considering piles B-PC2, B-PC4 and B-PC5 shows the development of a direct shear mechanism between the outer pile toe and the tunnel knee.

Volumetric strains are shown in Fig. 12(b) and are indicative of a 3D mechanism. Piles A-PC2, A-PC4 and A-PC5 all exhibited dilatancy below the pile toes, which was a function of clay from behind the pile filling the gap created by the tunnelling movements. Similarly for piles A-PC6, B-PC2, B-PC4 and B-PC5, contractile strains were apparent beneath the pile toe as clay on the plane of symmetry was forced behind the pile. Pile B-PC6 showed little change, which agrees with the little change in pile base load. For PC6 a camera fault resulted in lost data between pile A-PC6 and the tunnel centre-line, and this is visible in Fig. 12(a) and 12(b). As the soil remained undrained, the perceived volume changes at the pile toe are only due to the $2 \mathrm{D}$ formulation of the shear strain calculation along the plane of symmetry. The 3D mechanism allows soil to be either forced away or towards the plane of symmetry at the pile toes; this appears in the calculation as contraction and dilation, respectively. 


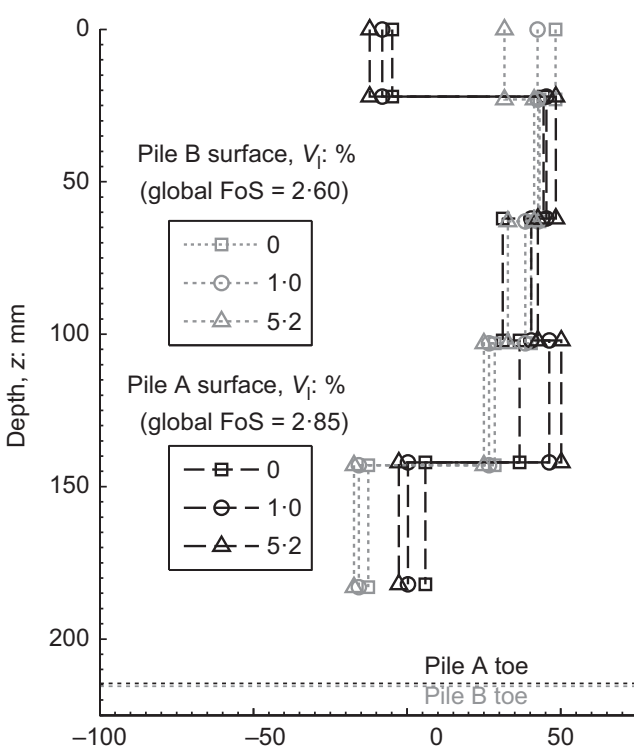

(a)

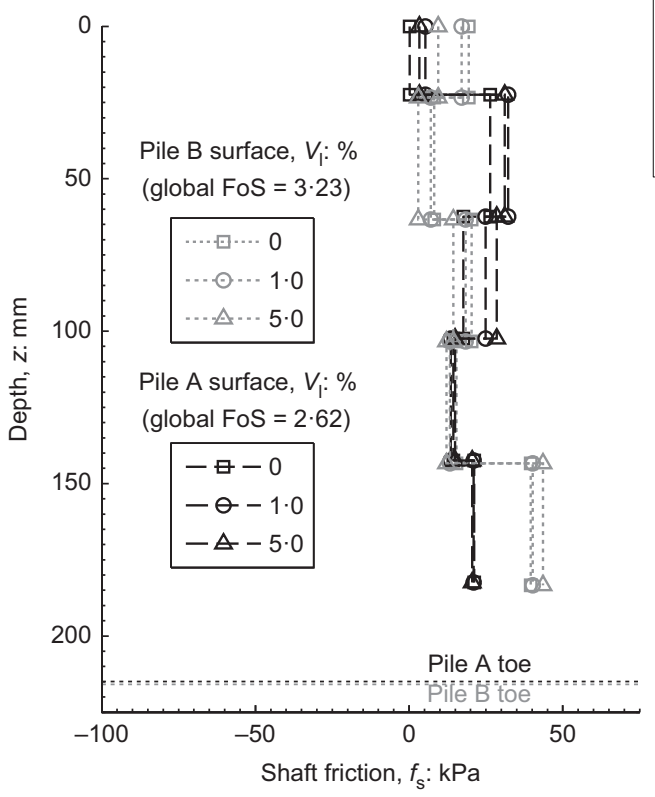

(c)

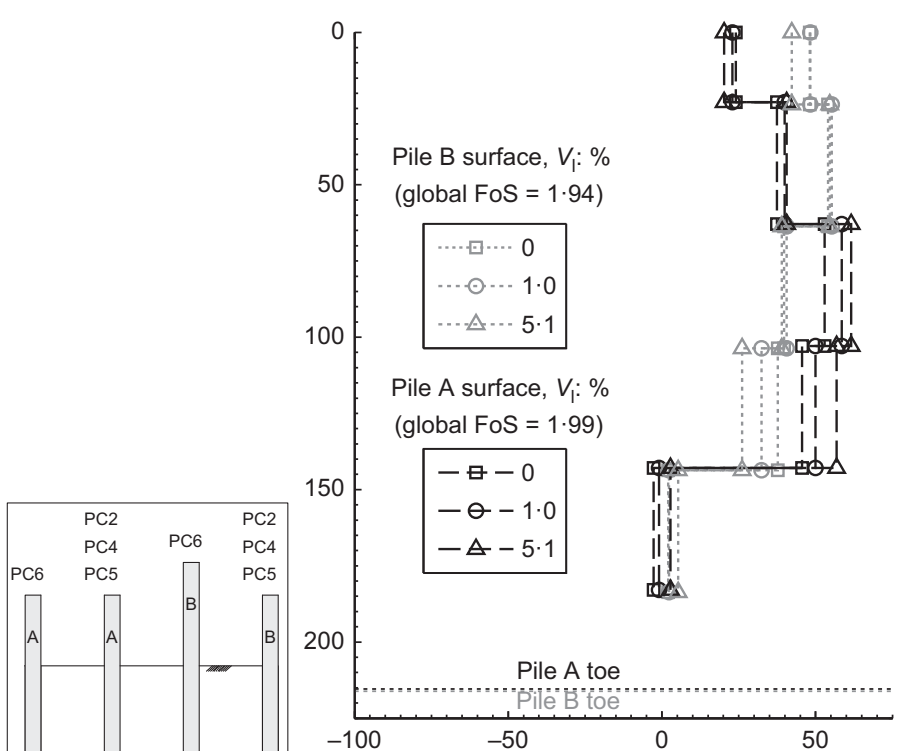

(b)

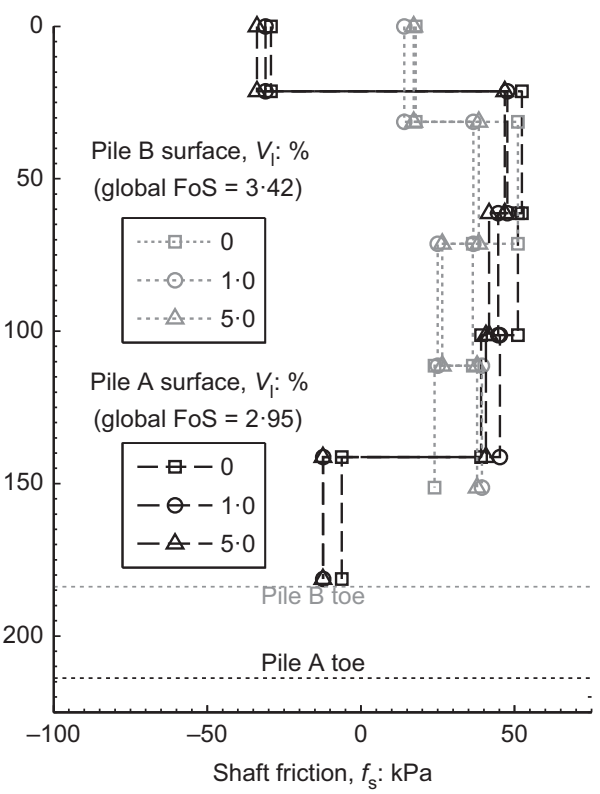

(d)

Fig. 10. Variations in shaft friction with volume loss. (a) PC2: reference test; (b) PC4: low FoS test; (c) PC5: low $E_{\text {soil }}$ test; (d) PC6: offset test

\section{Discussion}

The data presented thus far have shown that the experimental methodology produced high-quality and detailed information about pile behaviour that enabled the development of relatively simple TSAM analytical tools as detailed in the section on 'Comparison with 'greenfield' settlements and analytical modelling'. The innovative PIV set-up has been shown to be capable of providing new data for the interpretation of subsurface mechanisms and understanding of the load changes induced in piles. The data showed the following.

(a) Piles above the centre-line (piles A-PC2, A-PC4 and A-PC5) showed vertical displacements that were consistently greater than the soil settlements at the surface (in the case of the low-FoS test A-PC4, the vertical pile displacements were much greater). The PIV subsurface settlements shown in Fig. 11(a) are consistent with the changes in pile loading and shaft friction shown in Figs 9 and 10. In the lower parts of the piles, the soil settlement was greater than the pile settlement, which induced negative relative displacement and a reduction in skin friction; the upper parts of the piles were subjected to positive relative displacement with an associated increase in skin friction. Pile A-PC4 showed little change in skin friction in the lower part of the pile; this is a result of the initial loading being greater than for piles A-PC2 and A-PC5 and therefore the neutral axis (the point of change between positive and negative shaft friction) was lower down the pile.

(b) Piles away from the tunnel centre-line (piles B-PC2 and B-PC5) exhibited settlements lower than the soil settlements at the surface. When the pile displacements are compared with the PIV data in Fig. 11(a) and the pile loading and shaft friction in Figs 9 and 10, very little load change can be seen in the piles, mostly showing an increase in pile load due to positive relative displacement. In the case of pile B-PC4 (which showed settlements greater than the soil settlements at the 

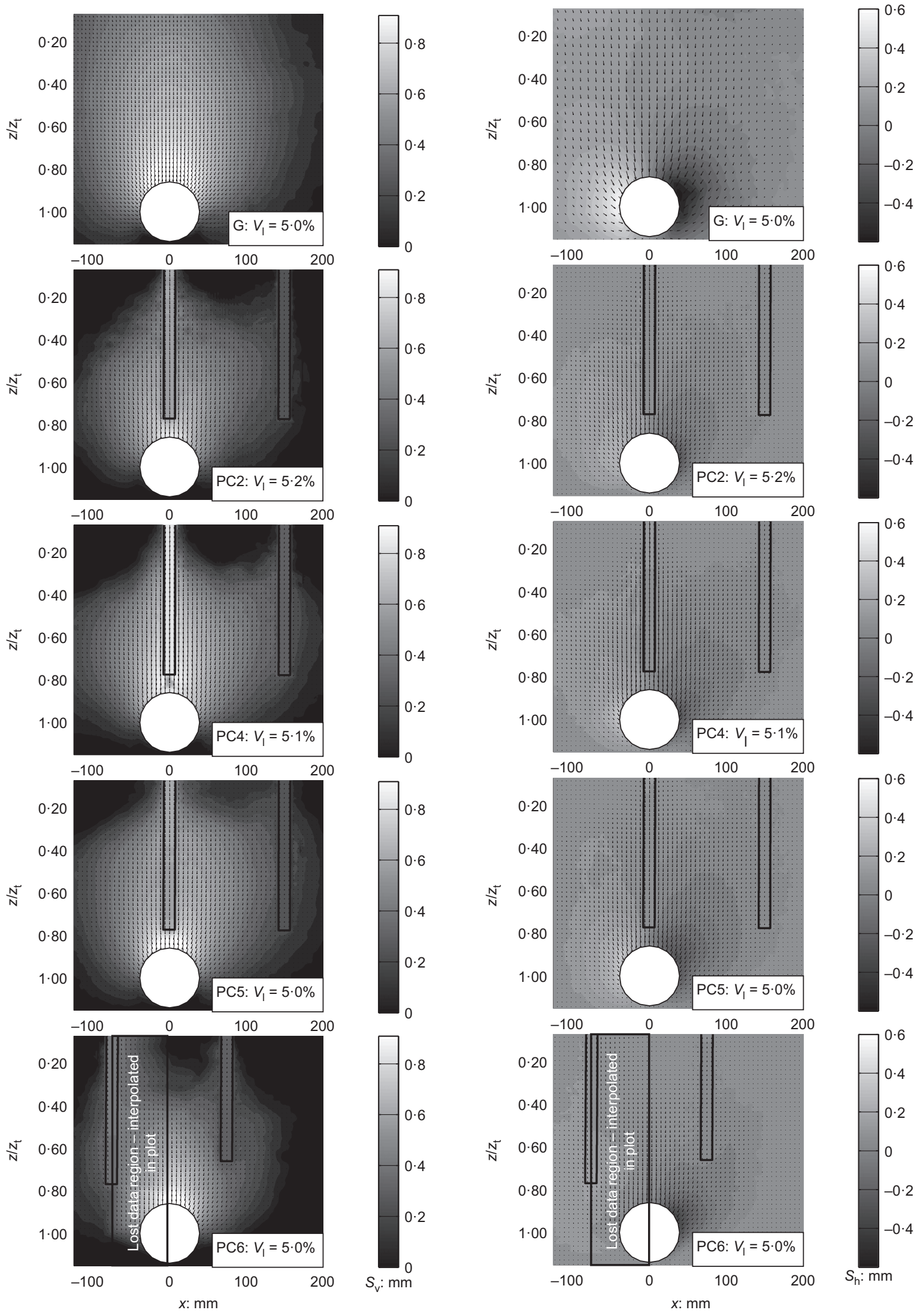

(a)

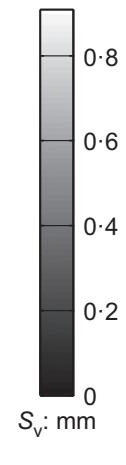

(b)

Fig. 11. PIV-measured soil movements: (a) vertical settlements; (b) horizontal settlements

surface), the subsurface PIV displacements would appear to show positive relative displacement and, again, an increase in load at depth and in particular in the base load. (c) Piles on the tunnel shoulders (piles A-PC6 and B-PC6) exhibited different behaviour. Pile A-PC6 showed an increase in pile load with volume loss, as expected with an increasing displacement profile with 

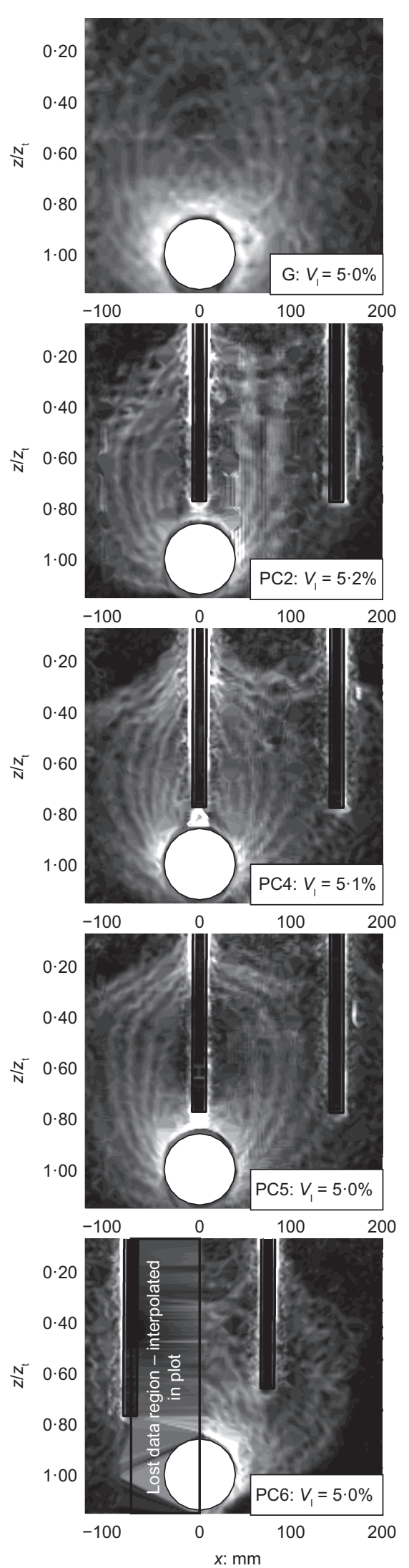

(a)
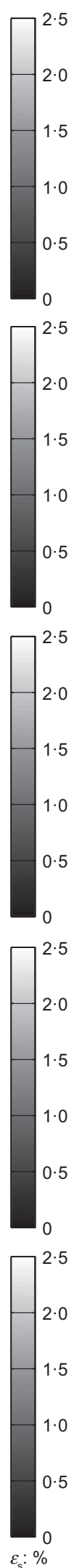
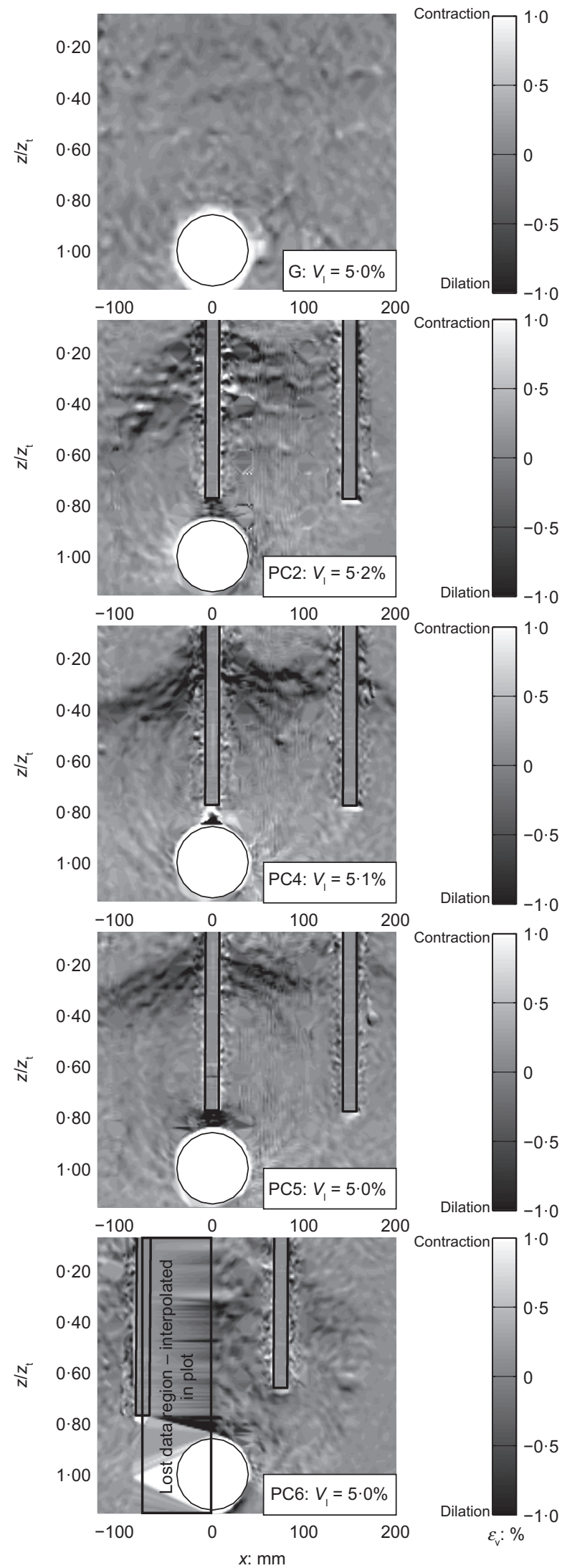

(b)

Fig. 12. PIV-measured soil strains: (a) shear strains; (b) volumetric strains

depth at this location resulting in negative skin friction applied in the upper pile and positive skin friction in the lower pile. This agrees with the subsurface PIV data where the soil close to the lower part of the pile appeared to settle less than the pile, whereas the opposite was true in the upper part of the pile. Pile B-PC6 showed an increase in pile load along the pile, but little increase at the pile base. This again agrees 
with the subsurface PIV data, where little relative movement can be seen between the pile base and the adjacent soil - this is best seen in Fig. 12(a) with zero volumetric strain below the pile - and greater discrepancy at mid-pile.

(d) For piles that are shaft controlled (as is the case for most non-displacement piles), there would appear to be no 'loss of capacity' - only pile settlement and load redistribution within the shaft. The experiments indicate the importance of the pile head load (and the associated global FoS, including the base load contribution) as this has an impact on the settlements and initial and final load distributions within the pile.

Based on the data presented, the observed mechanisms of pile behaviour appear to generally agree with a TSAM approach in that the mechanisms appear to be able to be explained by positive and negative relative displacements when compared against greenfield settlements. The effect of the piles on the greenfield soil displacements can be seen immediately adjacent to the piles but much less so further away, again indicating the small interaction effect between piles (with the exception of the heavily loaded PC4). Hence, a TSAM approach where the piles are analysed as single piles using greenfield soil displacement inputs would appear to be appropriate (as opposed to assessing a group of piles with significant interaction effects).

In the next section, in order to assess whether simple TSAMs are able to predict the behaviour observed in the testing series, a number of $t-z$ models were developed to attempt to model the behaviour of the piles in the tests. The $t-z$ models are able to account for pile head load, initial pile loading, reduction in base loading and positive and negative skin friction, as well as non-linear behaviour and interface plastic slip.

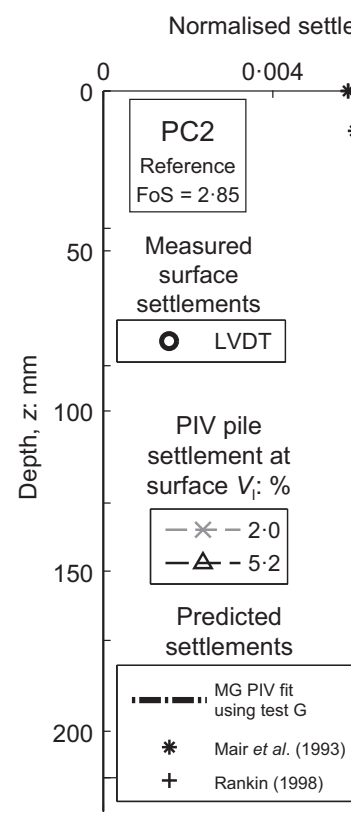

ment $/ V_{1},\left(S_{v} / D_{\mathrm{p}}\right) / V_{1}: \%-1$
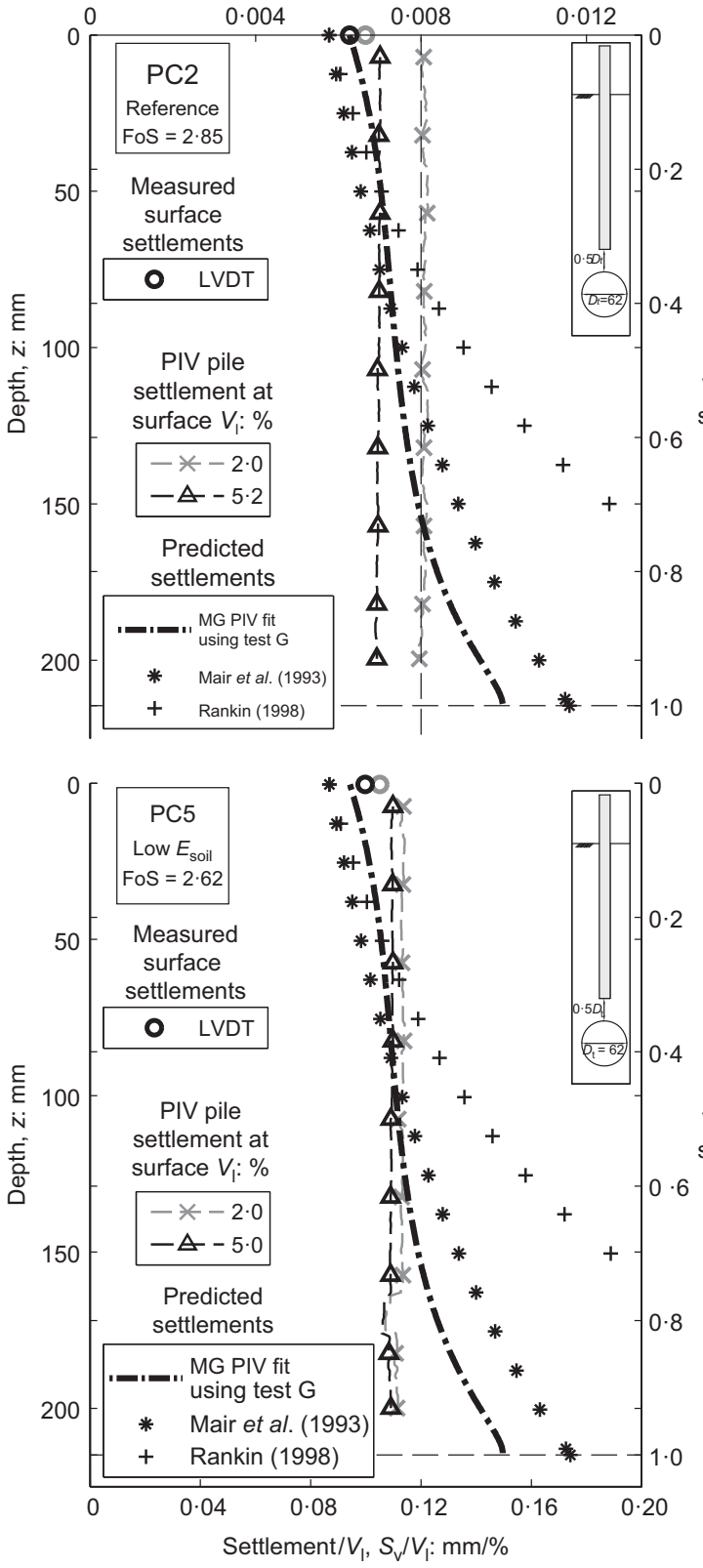

Normalised settlement $/ V_{l},\left(S_{v} / D_{\mathrm{p}}\right) / V_{\mathrm{l}}: \%{ }^{-1}$
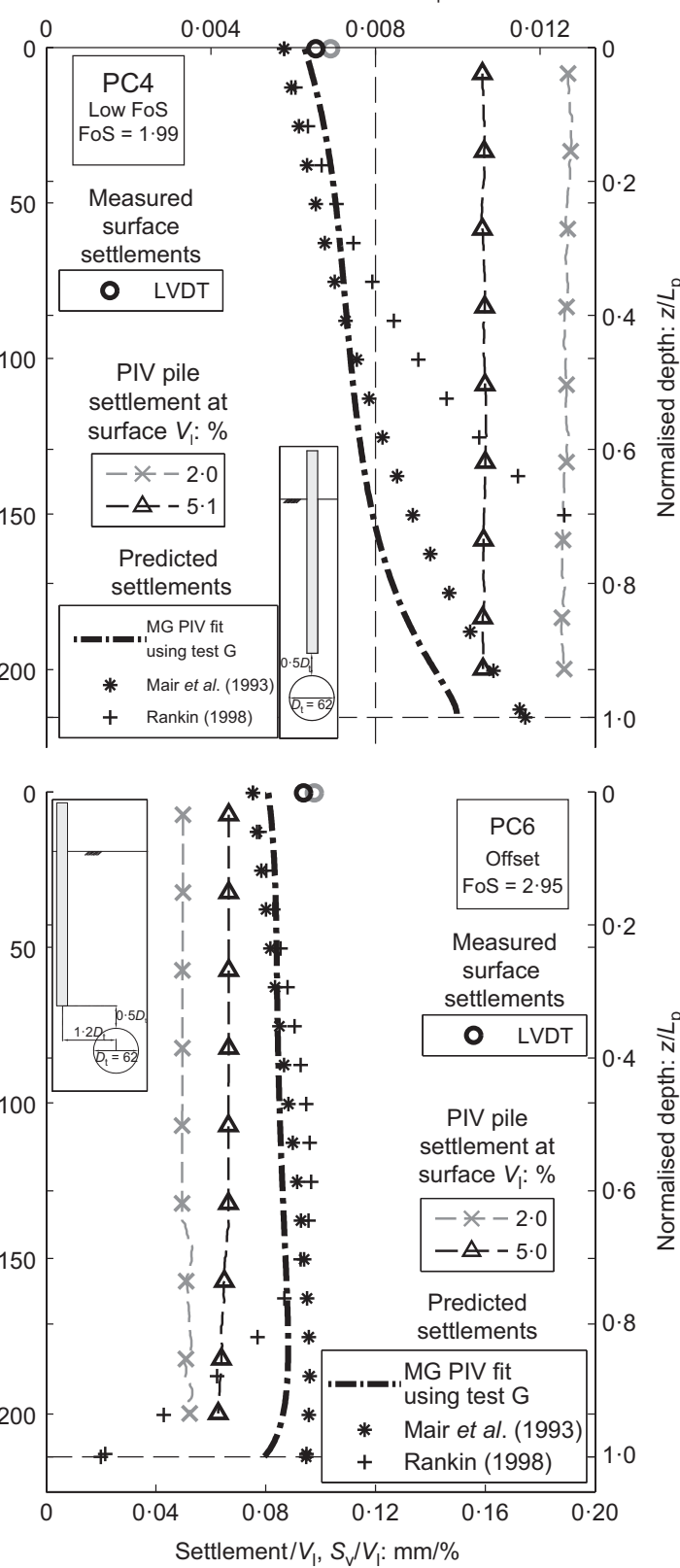

(a)

Fig. 13. Greenfield settlement models plotted against pile displacements: (a) pile A; (b) pile B (continued on next page) 

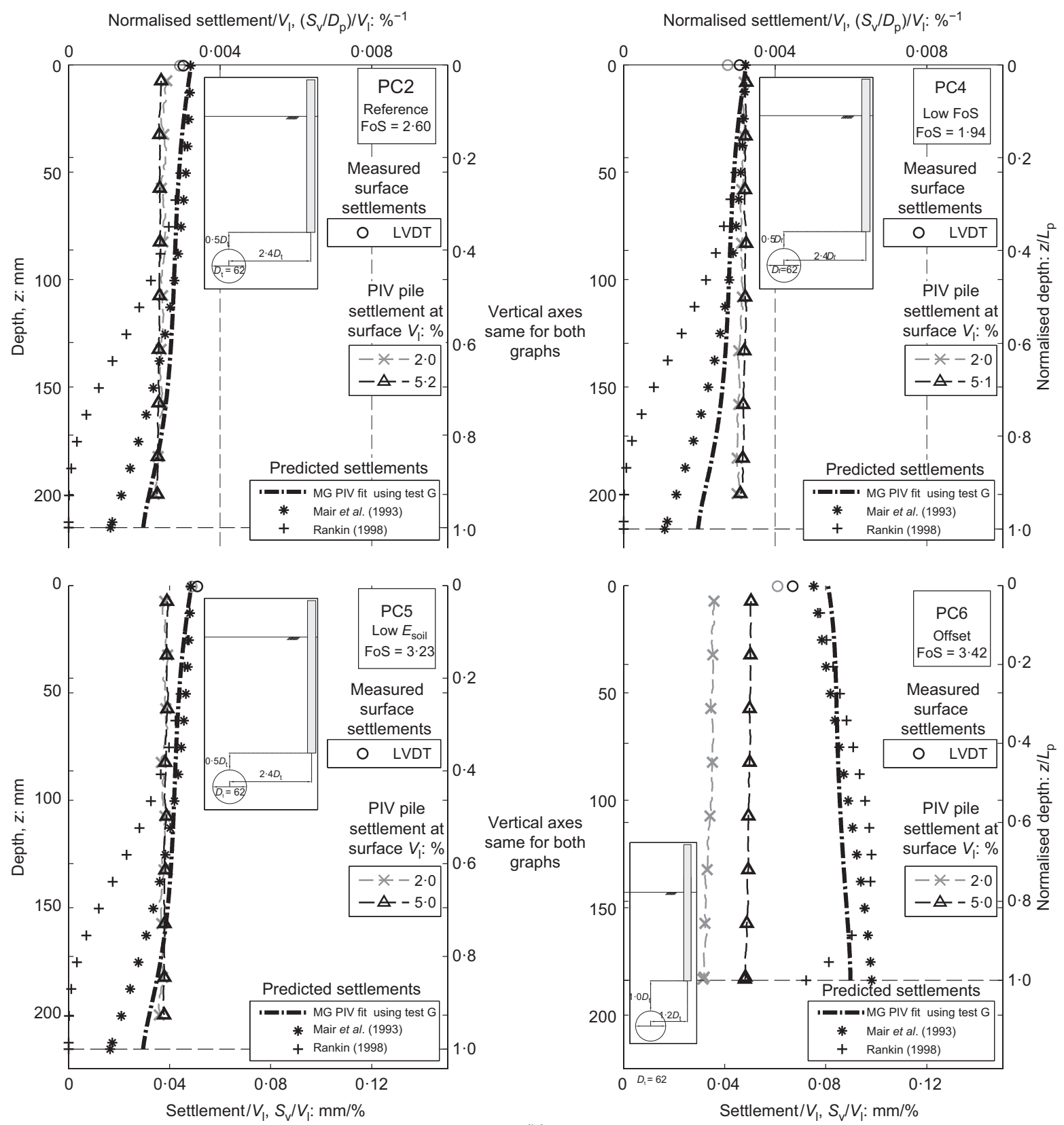

Fig. 13. Continued

\section{COMPARISON WITH 'GREENFIELD'}

SETTLEMENTS AND ANALYTICAL MODELLING

Comparison of pile settlements with 'greenfield' settlements

In this section the vertical pile displacements are compared with the greenfield settlements from test $\mathrm{G}$, assuming that the soil movements at the volume losses of interest $(<5 \%)$ within the region of the piles were consistent despite discrepancies in strength and stiffness. Fig. 13 compares pile displacements with those based on a modified Gaussian (Vorster et al., 2005) fit to the test $G$ displacements (see Williamson, 2014); also shown in the plots are the LVDT displacements at the locations behind the piles, for comparison with the PIV data. The equivalent subsurface soil settlements predicted by Mair et al. (1993) and Rankin (1988) are also shown as both models are used to predict open-face tunnelling movement. Both models over-predicted settlements at the centre-line piles (A-PC2, A-PC4 and A-PC5), under-predicted at the offset piles (B-PC2, B-PC4 and B-PC5) and predicted similar results for piles at the tunnel shoulders (A-PC6 and B-PC6).
The following pertinent points can be made from the results shown in Fig. 13.

(a) LVDT settlements are sometimes over- or under-predicted by the modified Gaussian (MG) method, particularly for PC6.

(b) The location of the equivalent level (the level at which the pile displacements match the greenfield settlements) varies with pile location and pile FoS. For PC4 and PC6, the pile displacements are not bounded by the greenfield settlements, particularly at lower volume losses; as $t-z$ models bound the problem with the greenfield settlements between the pile head and toe, they would be unable to simulate this behaviour.

(c) For any type of assessment of pile displacements from greenfield settlements, the assumed subsurface settlement profile will greatly influence the calculated settlements. 
Comparison of pile settlements with $\mathrm{t}-\mathrm{Z}$ models

Four different $t-z$ models were used in this research programme to simulate the centrifuge results

(a) perfectly plastic (PP) (neutral axis) model

(b) linear elastic (LE) model

(c) bilinear linear elastic-perfectly plastic (LEPP) model

(d) power-law non-linear elastic-perfectly plastic (NLEPP) model.

The idealised load-transfer behaviour of each model is shown in Fig. 14 and these were used as inputs to the Winkler assumption shown in Fig. 15.

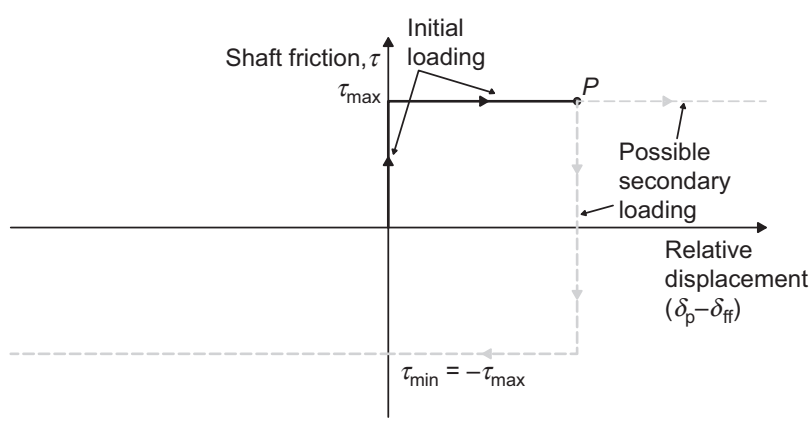

(a)

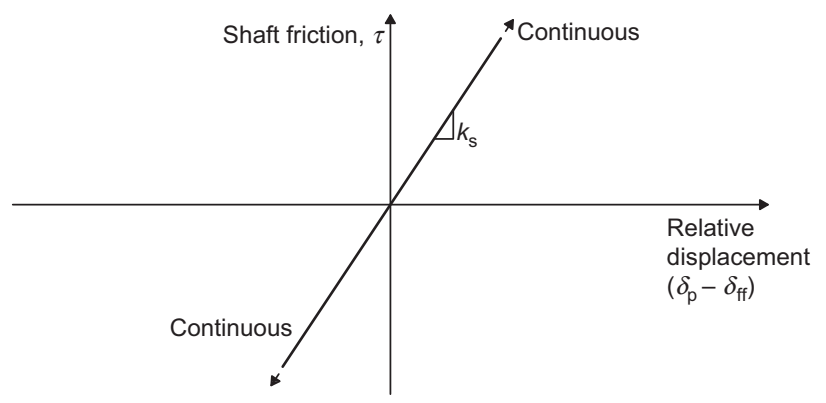

(b)

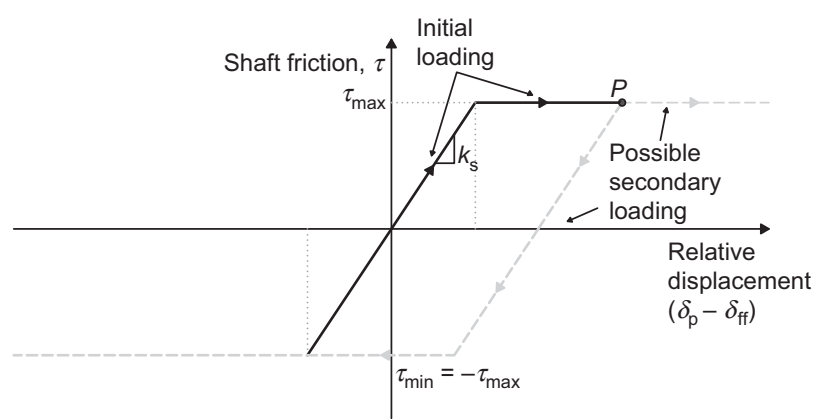

(c)

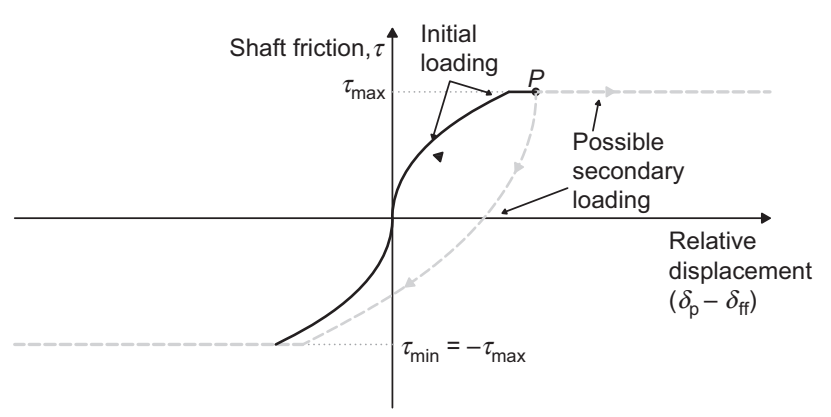

(d)

Fig. 14. $t-z$ Models: (a) PP (neutral axis); (b) LE; (c) LEPP; (d) NLEPP

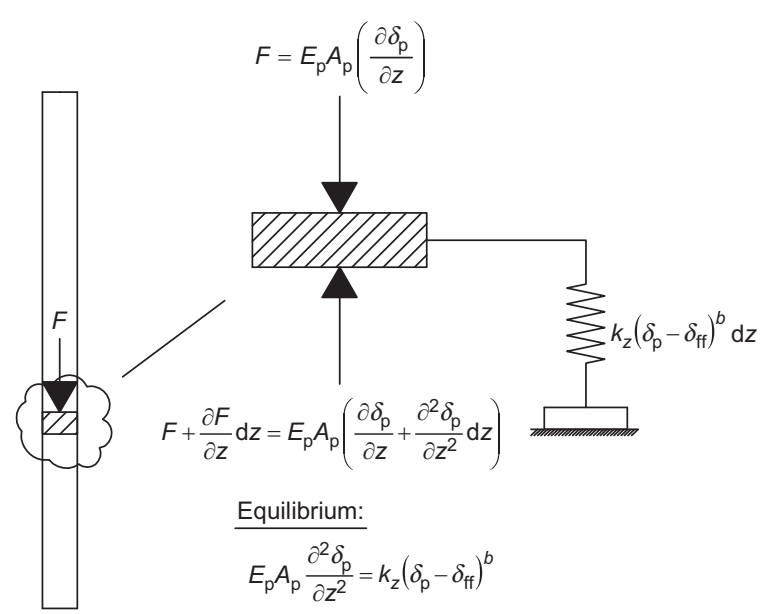

Fig. 15. Winkler spring idealised pile element

As discussed in the companion paper (Williamson et al., 2017) simulating the full centrifuge testing process is necessary to accurately model the pile behaviour. As such, three stages were modelled

(a) preloading: laboratory floor/spin-up/consolidation stress changes and soil movements applied

(b) pile head loading: application of head loading in the centrifuge

(c) volume loss: tunnelling volume loss settlements applied.

The preloading movements were modelled as in Williamson et al. (2017) and the volume loss movements were modelled using the soil settlement profiles given in Fig. 13. The PP, LE and the LEPP models are described in detail by Williamson (2014) and are therefore not repeated here other than to note some of the following pertinent points about the results.

(a) The PP model is most appropriate at much larger volume losses than those discussed in this paper.

(b) The LE model significantly over-estimates the change in model loading when subjected to volume loss due to a lack of plasticity (pile-soil slip).

(c) The LEPP model provides a better estimation of the load changes due to the incorporation of plasticity in the model. However, the selection of a single soil stiffness for all of the stages in the tests described above is extremely difficult. This results in over-prediction of load changes without stress reversal, as the modelled soil stiffness upon continued loading is over-estimated.

The NLEPP model presented in this paper addresses some of the issues with the PP, LE and LEPP models as it is able to model plasticity in the form of limiting skin friction, is equally applicable to low volume losses and high volume losses, provides an interface stiffness that varies with strain and allows the modelling of increased stiffness upon stress reversal.

The non-linear analysis presented here is based on the power-law model described in the companion paper, which is based on the work of Vardanega et al. (2012a). The advantage of this model is that the stress-strain relationship is based on a series of triaxial tests (Vardanega et al. (2012b) carried out tests on the same batch of clay as the centrifuge tests), the shear strength is calculated from the stress history and only the input consolidation and greenfield movements are required as further inputs. As such, the model can be applied to any test series, with triaxial stress-strain curves 
and predicted open-face tunnelling movements, without the need for any form of curve fitting or selection of strain level.

NLEPP $\mathrm{t}-\mathrm{z}$ model. A non-linear power-law soil stiffness model was used for the $t-z$ model as described by Williamson et al. (2017) and shown in Fig. 14(d). For the non-linear Winkler springs, the same assumptions for relative displacement were made as for the linear Winkler springs, with the load-transfer curve a function of the relative displacement, not the pile displacement. The shape of the $t-z$ curve varied for each pile element based upon the soil stress history of the adjacent soil element. The non-linear input parameters for stiffness and calculated undrained shear strength are provided in figure 14 of Williamson et al. (2017). Reversal in relative displacement applied the Masing rule as shown in Fig. 14(d), which was utilised to provide a stiffer response with stress reversal. The pile base followed the model described by Williamson et al. (2017) with the addition of the Masing rule upon a change in relative displacement, which allows for lift-off when the contact load reduces to zero.

Predicted pile head displacements are shown in Fig. 16 for the initial pile loading stage. The variation between the base
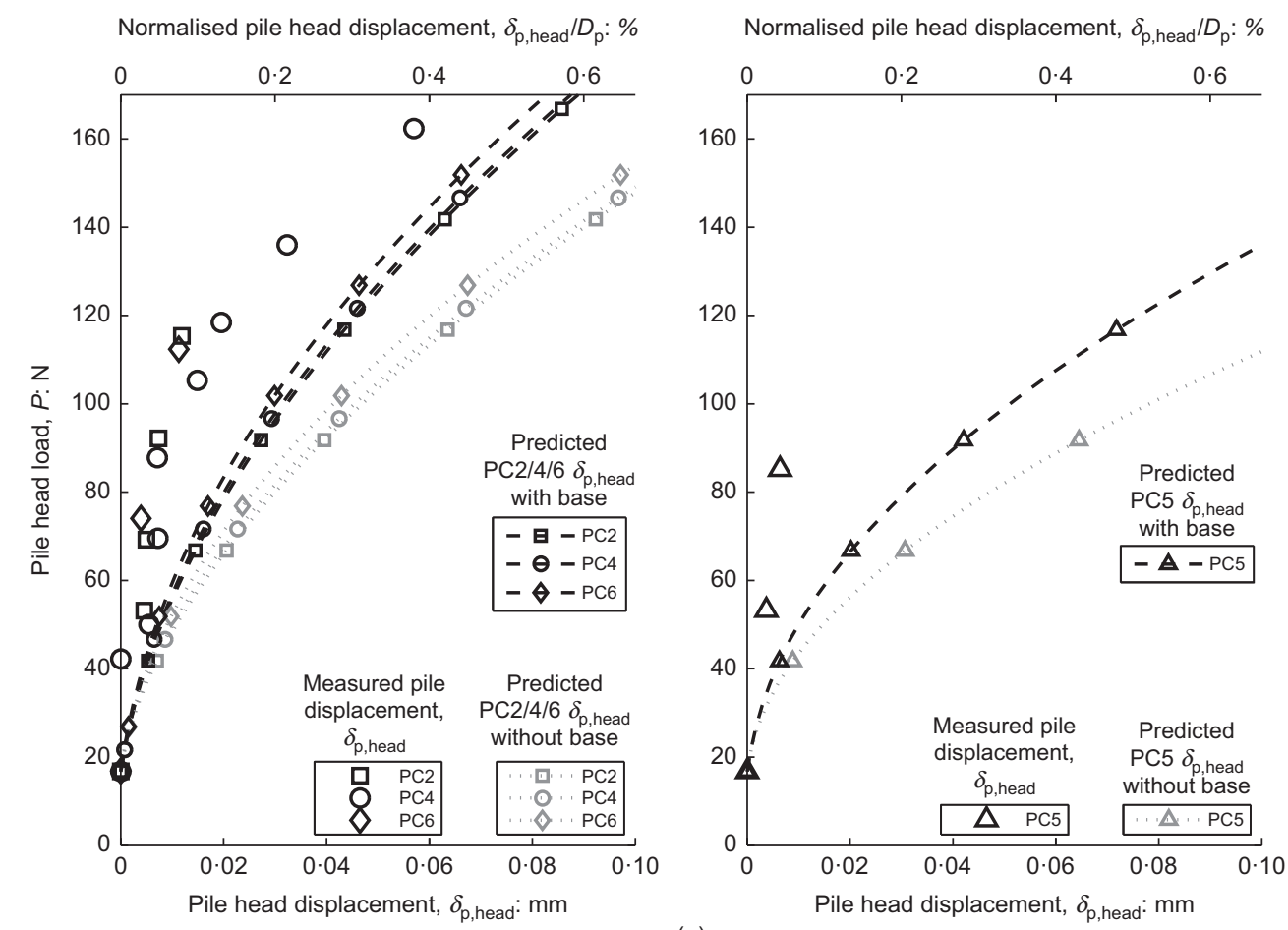

(a)
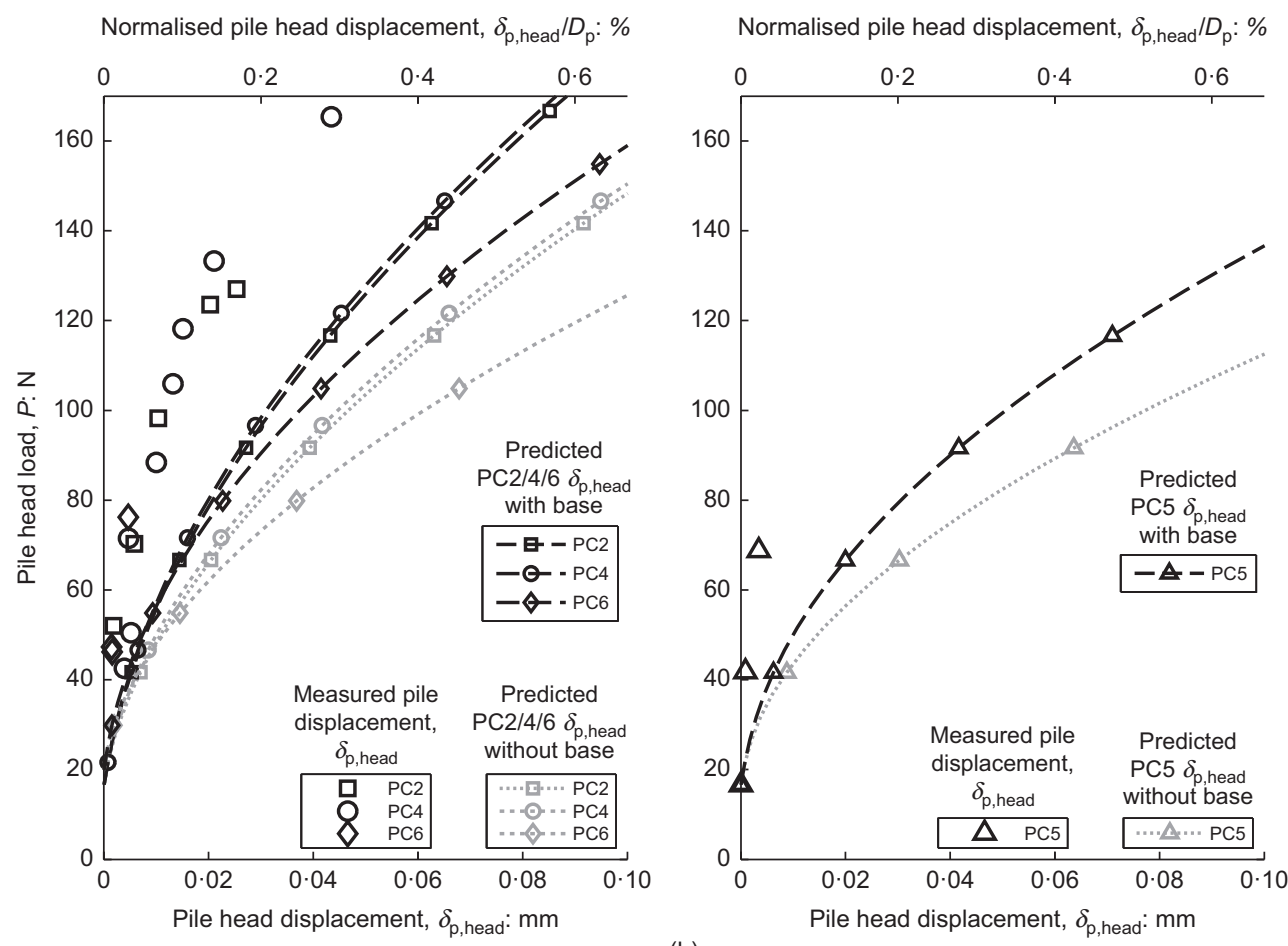

(b)

Fig. 16. Measured and predicted (NLEPP) pile head load against pile head settlement: (a) pile A; (b) pile B 
and non-base cases is quite pronounced, alongside the effect of soil non-linearity. It is clear that the soil response was stiffer than the predictions of the NLEPP model; however, the non-linearity of the curves is reasonable, as are the shapes of the curves at higher loads, although the initial stiffnesses of the actual piles were greater than the modelled values.

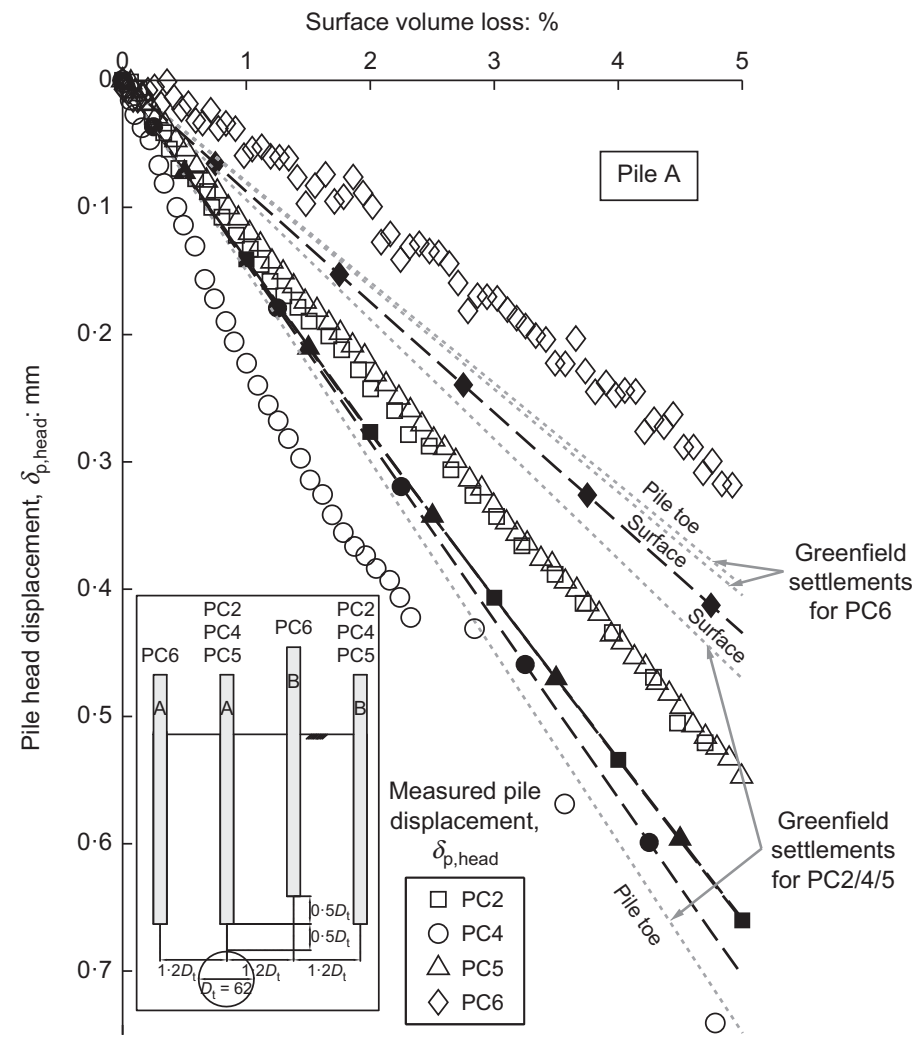

(a)

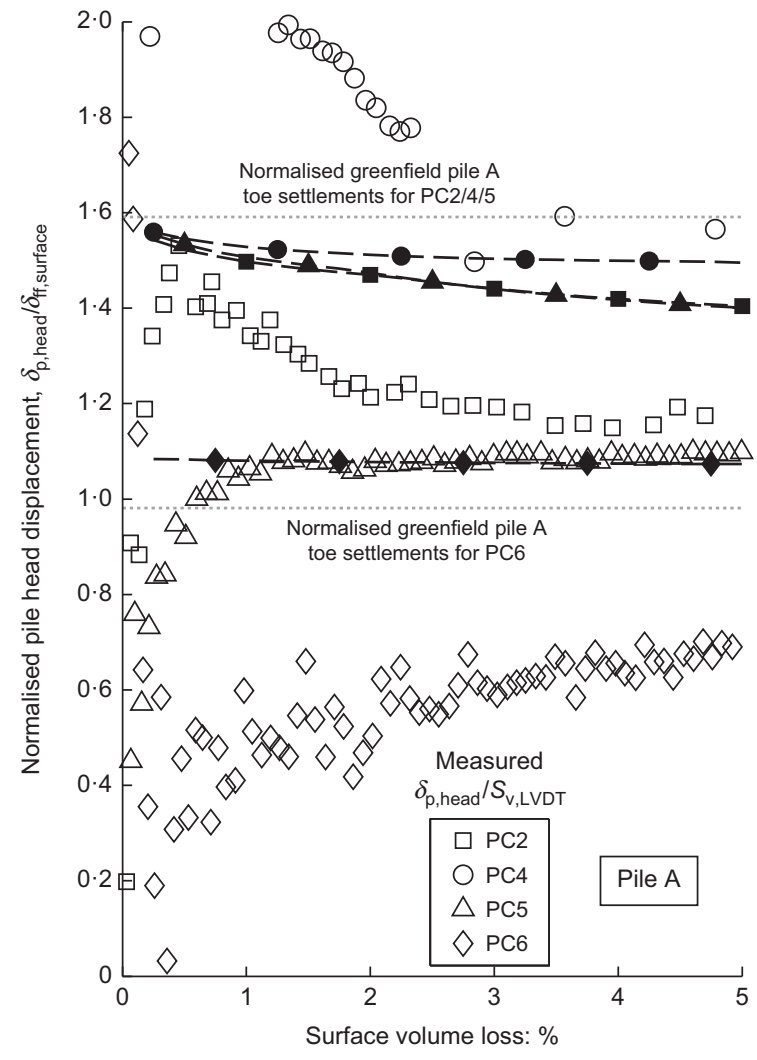

(b)
For the volume loss stage, the predicted pile head displacements, normalised pile head displacements and changes in loads are shown in Figs 17(a), 17(b) and 18, respectively. The shape of the graphs for pile A and pile B are well modelled with the exception of test PC6, which was limited by the input settlement profile. The model
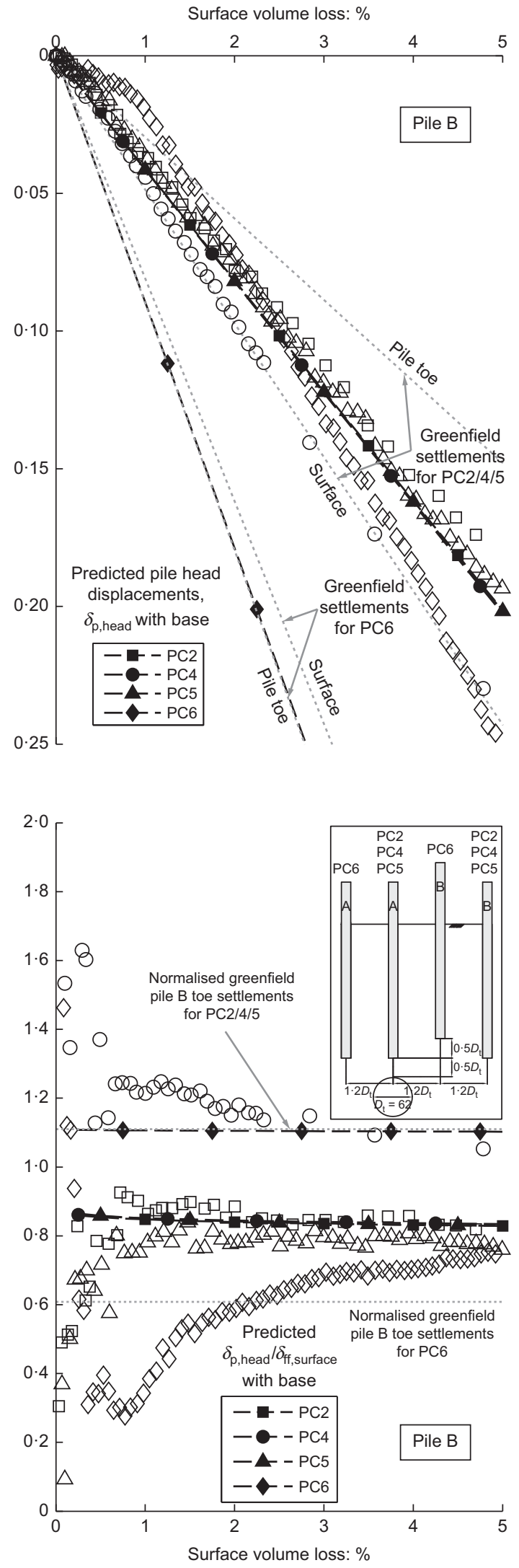

Fig. 17. (a) NLEPP pile head settlement plotted against volume loss. (b) Normalised NLEPP pile head settlement plotted against volume loss 

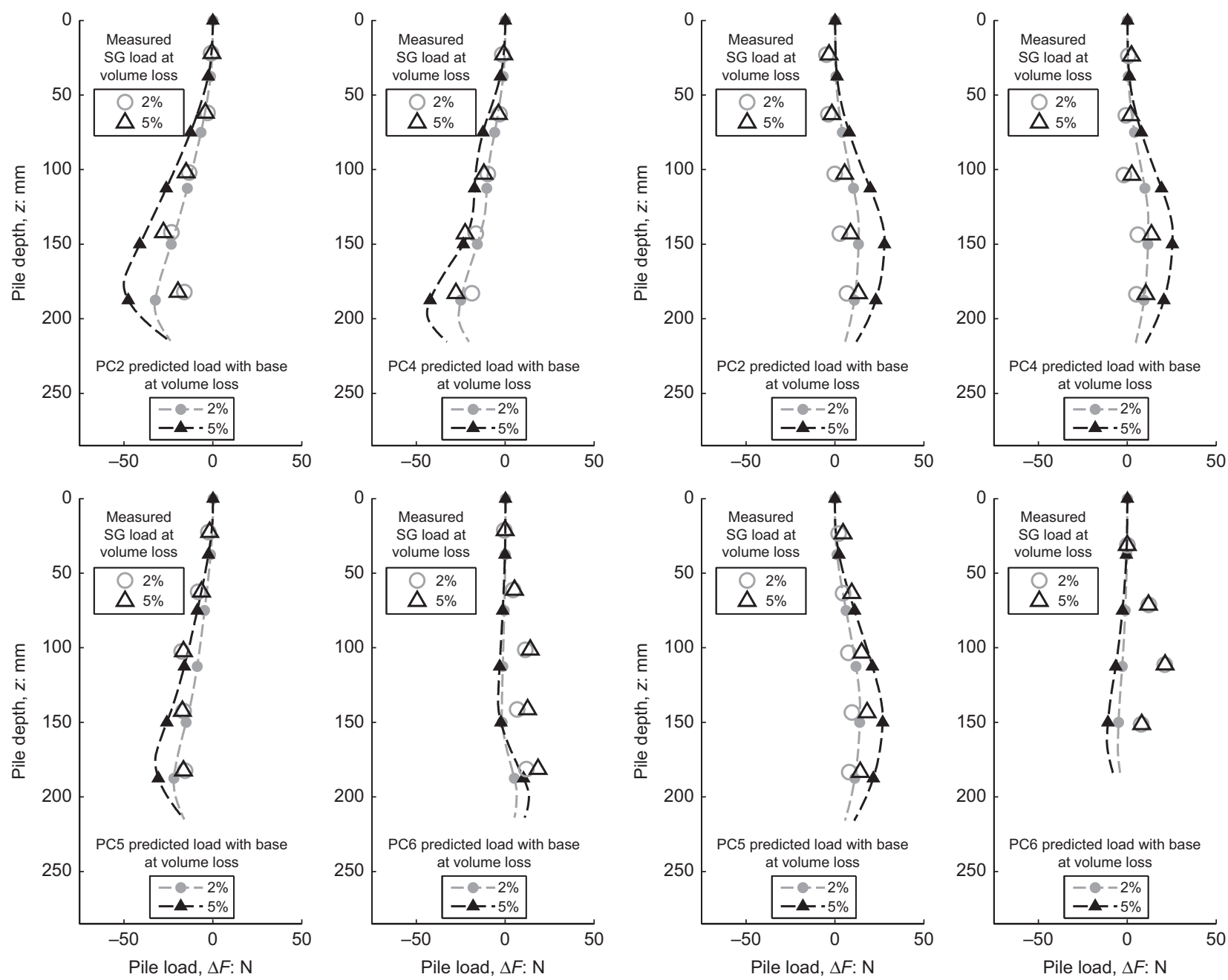

(a)

(b)

Fig. 18. Change in load (predicted by NLEPP and measured by strain gauge (SG)) plotted against pile depth for different volume losses: (a) pile A; (b) pile B

underestimated the movements of both piles for PC4, which, again, was limited by the input settlement profile.

Considering the pile loading in Fig. 18, the predictions of change in load are relatively good, particularly for the pile A cases where the predictions are reasonable for both the magnitude and shape with depth. For piles B-PC2, B-PC4 and B-PC5 the shape of the plots are good, but the model generally over-predicts the magnitude (although for B-PC5 the loadings are within 20\%). Again, pile B-PC6 was limited by the input settlements and this is the lateral location where the soil settlements either side of the pile were very different (one increasing with depth along the pile length and one reducing with depth along the pile length).

\section{CONCLUSIONS}

(a) A series of centrifuge tests was performed to attempt to characterise the behaviour of individual piles when subjected to tunnelling movements.

(b) Both increasing, decreasing and nearly uniform settlement with depth profiles were applied to the piles by varying the pile positioning.

(c) The use of PIV allowed investigation of the subsurface pile-soil interaction and showed that the assumed mechanisms of pile-soil interaction or positive/negative relative displacement would appear to be an appropriate model for single piles. (d) The effects of pile loading and actual pile safety factors were investigated; a reduced FoS was found to increase settlements.

(e) The effect of consolidation settlements in centrifuge testing were found to have a significant influence on pile behaviour and must be modelled carefully if used for the validation of numerical models.

( $f$ ) $t-z$ modelling with a power-law NLEPP model was found to be able to predict the pile response to loading and tunnelling movements and was able to capture the shape of both the pile settlement response with volume loss and the change in pile loads. However, such a model is limited by the input settlement profile and cannot predict movements that are either greater or less than these values.

(g) Inclusion of plasticity in the models is very important, as LE models will over-predict loading and load changes.

(h) Modelling using a $t-z$ model showed that consideration of the initial loading is important, especially where the lower pile is loaded at working load.

(i) There would appear to be some group behaviour, particularly in the case of heavily loaded piles where the soil between piles is more heavily stressed and hence provides a softer response than a single pile might be expected to exhibit. 


\section{ACKNOWLEDGEMENTS}

The first author acknowledges financial support provided by Arup Tunnelling and the Engineering and Physical Sciences Research Council for an Industrial Case Studentship. The significant support provided by technical staff of both the Schofield Centre and Cambridge University Engineering Department is greatly appreciated.

\section{NOTATION}

$A_{\mathrm{p}}$ cross-sectional area of pile

$b$ power coefficient in power-law stress-strain model

$c_{\mathrm{u}} \quad$ undrained shear strength of soil

$D_{\mathrm{p}}$ pile diameter

$D_{\mathrm{t}}$ tunnel diameter

$E_{\mathrm{p}} \quad$ Young's modulus of pile

$E_{\text {soil }} \quad$ Young's modulus of soil

$F$ pile load

$f_{\mathrm{s}}$ mobilised shaft friction of pile

$g$ acceleration due to gravity

$H_{\mathrm{c}}$ height of clay

$k_{\mathrm{s}}$ slope of $t-z$ curve

$k_{z}$ nodal soil stiffness

$L_{\mathrm{p}} \quad$ length of pile

$P$ pile head load

$S_{\mathrm{h}}$ horizontal movement

$S_{\mathrm{v}} \quad$ vertical settlement

$S_{\mathrm{v}, \mathrm{LVDT}} \quad$ vertical free-field soil settlement at the soil surface measured via LVDT

$V_{1}$ volume loss calculated from integrating the soil settlement trough

$x \quad$ lateral position relative to tunnel centre-line

$x_{\mathrm{A}}, x_{\mathrm{B}}, x_{\mathrm{C}}$ lateral position of pile relative to tunnel centre-line for pile $\mathrm{A}, \mathrm{B}$ and $\mathrm{C}$, respectively

$z$ depth from surface of clay

$z_{\mathrm{t}} \quad$ depth from surface of clay to tunnel axis

$\alpha$ shaft adhesion factor

$\Delta F \quad$ change in pile load

$\delta_{\mathrm{ff}}$ free-field vertical soil settlement

$\delta_{\mathrm{ff} \text { surface }}$ free-field vertical soil settlement at the soil surface

$\delta_{\mathrm{p}}$ pile displacement

$\delta_{\mathrm{p}, \text { head }}$ pile head displacement

$\delta_{\mathrm{p}, \text { head }} / D_{\mathrm{p}} \quad$ normalised pile head displacement

$\delta_{\mathrm{p}} / D_{\mathrm{p}} \quad$ normalised pile displacement

$\varepsilon_{\mathrm{s}} \quad$ shear strain

$\varepsilon_{\mathrm{v}} \quad$ volumetric strain

$\tau_{\max } \quad$ maximum mobilised shear stress

$\tau_{\text {mob }}$ mobilised shear stress

\section{REFERENCES}

Basile, F. (2014). Effects of tunnelling on pile foundations. Soils Found. 54, No. 3, 280-295.

Chen, L. T., Poulos, H. G. \& Loganathan, N. (1999). Pile responses caused by tunneling. ASCE J. Geotech. Geoenviron. Engng 125, No. 3, 207-215.

Cheng, C. Y., Dasari, G. R., Chow, Y. K. \& Leung, C. F. (2007). Finite element analysis of tunnel-soil-pile interaction using displacement controlled model. Tunn. Undergr. Space Technol. 22, No. 4, 450-466.

Chow, Y. K. (1986). Analysis of vertically loaded pile groups. Int. J. Numer. Analyt. Methods Geomech. 10, No. 1, 59-72.

Huang, M. \& Mu, L. (2012). Vertical response of pile raft foundations subjected to tunneling-induced ground movements in layered soil. Int. J. Numer. Analyt. Methods Geomech. 36, No. 8, 977-1001.

Huang, M., Zhang, C. \& Li, Z. (2009). A simplified analysis method for the influence of tunneling on grouped piles. Tunn. Undergr. Space Technol. 24, No. 4, 410-422.

Jacobsz, S. W. (2002). The effects of tunnelling on piled foundations. $\mathrm{PhD}$ thesis, University of Cambridge, Cambridge, UK.

Jacobsz, S. W., Standing, J. R., Mair, R. J., Hagiwara, T. \& Sugiyama, T. (2004). Centrifuge modelling of tunnelling near driven piles. Soils Found. 44, No. 1, 49-56.
Jacobsz, S. W., Bowers, K. H., Moss, N. A. \& Zanardo, G. (2005). The effects of tunnelling on piled foundations on the CTRL. In Proceedings of the 5th international symposium on geotechnical aspects of underground construction in soft ground (eds $\mathrm{K}$. J. Bakker, A. Bezuijen, W. Broere and E. A. Kwast), pp. 115-121. Rotterdam, the Netherlands: Balkema.

Kaalberg, F. J., Teunissen, E. A., van Toi, A. F. \& Bosch, J. W. (2005). Dutch research on the impact of shield tunnelling on pile foundation. In Proceedings of the 5th international symposium on geotechnical aspects of underground construction in soft ground (eds K. J. Bakker, A. Bezuijen, W. Broere and E. A. Kwast), pp. 123-131. Rotterdam, the Netherlands: Balkema.

Kitiyodom, P., Matsumoto, T. \& Kawaguchi, K. (2004). Analysis of piled raft foundation subject to ground movement induced by tunnelling. In Proceedings of the 15th Southeast Asian geotechnical conference (eds S. Sambhandharaksa, D. T. Bergado and T. Boonyatee), pp. 183-188. Pathumthani, Thailand: South East Asian Geotechnical Society (SEAGS).

Kitiyodom, P., Matsumoto, T. \& Kawaguchi, K. (2005). A simplified analysis method for piled raft foundations subjected to ground movements induced by tunnelling. Int. J. Numer. Analyt. Methods Geomech. 29, No. 15, 1485-1507.

Klar, A. \& Soga, K. (2005). The effect of ground settlements on the axial response of piles: some closed from solutions, Technical Report CUED/D-SOILS/TR341. University of Cambridge, Cambridge, UK.

Korff, M. (2012). Response of piled buildings to the construction of deep excavations. PhD thesis, University of Cambridge, Cambridge, UK.

Lee, C. J. (2012a). Numerical analysis of the interface shear transfer mechanism of a single pile to tunnelling in weathered residual soil. Comput. Geotech. 42, 193-203.

Lee, C. J. (2012b). Three-dimensional numerical analyses of the response of a single pile and pile groups to tunnelling in weak weathered rock. Tunn. Undergr. Space Technol. 32, $132-142$.

Lee, C. J. (2013). Numerical analysis of pile response to open face tunnelling in stiff clay. Comput. Geotech. 51, 116-127.

Lee, C. J. \& Chiang, K. H. (2007). Responses of single piles to tunneling-induced soil movements in sandy ground. Can. Geotech. J. 44, No. 10, 1224-1241.

Lee, G. T. K. \& Ng, C. W. W. (2005). Effects of advancing open face tunneling on an existing loaded pile. ASCE J. Geotech. Geoenviron. Engng 131, No. 2, 193-201.

Loganathan, N., Poulos, H. G. \& Stewart, D. P. (2000). Centrifuge model testing of tunnelling-induced ground and pile deformations. Géotechnique 50, No. 3, 283-294, http://dx.doi. org/10.1680/geot.2000.50.3.283.

Loganathan, N., Poulos, H. G. \& Xu, K. J. (2001). Ground and pile-group responses due to tunnelling. Soils Found. 41, No. 1, 57-67.

Mair, R. J. (1979). Centrifugal modelling in tunnel construction in soft clay. PhD thesis, University of Cambridge, Cambridge, UK.

Mair, R. J., Taylor, R. N. \& Bracegirdle, A. (1993). Subsurface settlement profiles above tunnels in clays. Géotechnique $\mathbf{4 3}$, No. 2, 315-320, http://dx.doi.org/10.1680/geot.1995.45.2.361.

Marshall, A. M. \& Mair, R. J. (2011). Tunneling beneath driven or jacked end-bearing piles in sand. Can. Geotech. J. 48, No. 12, $1757-1771$.

Mindlin, R. D. (1936). Force at a point in the interior of a semi-infinite solid. J. Appl. Phys. 7, No. 5, 195-202.

Mroueh, H. \& Shahrour, I. (2002). Three-dimensional finite element analysis of the interaction between tunneling and pile foundations. Int. J. Numer. Analyt. Methods Geomech. 26, No. 3, 217-230.

Pang, C. H., Yong, K. Y., Chow, Y. K. \& Wang, J. (2005). The response of pile foundations subjected to shield tunnelling. In Proceedings of the 5th international symposium on geotechnical aspects of underground construction in soft ground (eds K. J. Bakker, A. Bezuijen, W. Broere and E. A. Kwast), pp. 737-744. Rotterdam, the Netherlands: Balkema.

Poulos, H. G. \& Davis, E. H. (1980). Pile foundation analysis and design. New York, NY, USA: Wiley.

Randolph, M. F. \& Wroth, C. P. (1978). Analysis of deformation of vertically loaded piles. ASCE J. Geotech. Engng 104, No. 12, $1465-1488$. 
Rankin, W. J. (1988). Ground movements resulting from urban tunnelling: predictions and effects. Engineering Geology Special Publication 5, pp. 79-92. London, UK: Geological Society.

Schofield, A. N. (1980). Cambridge geotechnical centrifuge operations. Géotechnique 30, No. 3, 227-268, http://dx.doi.org/ 10.1680/geot.1980.30.3.227.

Selemetas, D., Standing, J. R. \& Mair, R. J. (2005). The response of full-scale piles to tunnelling. Proceedings of the 5th international symposium on geotechnical aspects of underground construction in soft ground (eds K. J. Bakker, A. Bezuijen, W. Broere and E. A. Kwast), pp. 763-769. Rotterdam, the Netherlands: Balkema.

Tomlinson, M. J. \& Woodward, J. (2008). Pile design and construction. London, UK: Taylor \& Francis.

Vardanega, P. J., Williamson, M. G. \& Bolton, M. D. (2012a). Bored pile design in stiff clay II: mechanisms and uncertainty. Proc. Insth Civ. Engrs - Geotech Engng 165, No. 4, 233-246, http:// dx.doi.org/10.1680/geng.11.00063.

Vardanega, P. J., Lau, B. H., Lam, S. Y., Haigh, S. K., Madabhushi, S. P. G. \& Bolton, M. D. (2012b). Laboratory measurement of strength mobilisation in kaolin: link to stress history. Géotech. Lett. 2, No. 1, 9-15, http://dx.doi.org/10.1680/ geolett.12.00003.

Vorster, T. E. B., Klar, A., Soga, K. \& Mair, R. J. (2005). Estimating the effects of tunnelling on existing pipelines. ASCE J. Geotech. Geoenviron. Engng 131, No. 11, 1399-1410.
Williamson, M. G. (2014). Tunnelling effects on bored piles in clay. $\mathrm{PhD}$ thesis, University of Cambridge, Cambridge, UK.

Williamson, M. G., Elshafie, M. Z. E. B., Mair, R. J. \& Devriendt, M. D. (2017). Open-face tunnelling effects on non-displacement piles in clay - part 1: centrifuge modelling techniques. Géotechnique, in press.

Xu, K. J. \& Poulos, H. G. (2001). 3-D elastic analysis of vertical piles subjected to 'passive' loadings. Comput. Geotech. 28, No. 5, 349-375.

Yoo, C. \& Kim, S. B. (2008). Three-dimensional numerical investigation of multifaced tunneling in water-bearing soft ground. Can. Geotech. J. 45, No. 10, 1467-1486.

Yoo, C. \& Wu, S. J. (2012). Interaction between tunnelling and bridge foundation - 3D numerical investigation. In Proceedings of the 7th international symposium on geotechnical aspects of underground construction in soft ground (ed. G. Viggiani), pp. 477-480. London, UK: Taylor \& Francis Group.

Zhang, R. J., Zheng, J. J., Zhang, L. M. \& Pu, H. F. (2011) An analysis method for the influence of tunneling on adjacent loaded pile groups with rigid elevated caps. Int. J. Numer. Analyt. Methods Geomech. 35, No. 18, 1949-1971.

Zhang, R. J., Zheng, J. J. \& Yu, S. (2013). Responses of piles subjected to excavation-induced vertical soil movement considering unloading effect and interfacial slip characteristics. Tunn. Undergr. Space Technol. 36, 66-79. 